Received: 5 October 2017

Accepted: 8 March 2018

Published online: 22 March 2018
CIENTIFIC REP

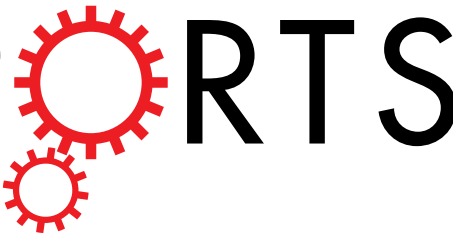

\section{OPEN Inhibitory effect of surface pre- reacted glass-ionomer (S-PRG) eluate against adhesion and colonization by Streptococcus}

\section{mutans}

\section{Ryota Nomura, Yumiko Morita, Saaya Matayoshi \& Kazuhiko Nakano}

Surface Pre-reacted Glass-ionomer (S-PRG) filler is a bioactive filler produced by PRG technology, which has been applied to various dental materials. A S-PRG filler can release multiple ions from a glass-ionomer phase formed in the filler. In the present study, detailed inhibitory effects induced by S-PRG eluate (prepared with S-PRG filler) against Streptococcus mutans, a major pathogen of dental caries, were investigated. S-PRG eluate effectively inhibited $S$. mutans growth especially in the bacterium before the logarithmic growth phase. Microarray analysis was performed to identify changes in S. mutans gene expression in the presence of the S-PRG eluate. The S-PRG eluate prominently downregulated operons related to $S$. mutans sugar metabolism, such as the $p d h$ operon encoding the pyruvate dehydrogenase complex and the glg operon encoding a putative glycogen synthase. The S-PRG eluate inhibited several in vitro properties of $S$. mutans relative to the development of dental caries especially prior to active growth. These results suggest that the S-PRG eluate may effectively inhibit the bacterial growth of $S$. mutans following downregulation of operons involved in sugar metabolism resulting in attenuation of the cariogenicity of $S$. mutans, especially before the active growth phase.

Streptococcus mutans has been implicated as a primary causative agent of dental caries in humans ${ }^{1}$. Although the mechanisms of dental caries have been well investigated and the incidence of dental caries has been reduced in most developing countries, eradication of dental caries remains difficult ${ }^{2}$. Thus, novel dental products for prevention of dental caries are under development in various countries ${ }^{3-5}$.

Surface Pre-Reacted Glass-ionomer (S-PRG) fillers have been synthesized by PRG technology involving reaction between fluoroboroaluminosilicate glass and a polyacrylic acid solution ${ }^{6}$. The S-PRG filler is used in various dental materials including composite resins, bonding agents, cements, and resin sealants ${ }^{7,8}$. In addition, research focusing on the usefulness of S-PRG fillers in oral hygiene products such as mouthwashes to inhibit the bacteria or oral malodour has been reported ${ }^{9}$. S-PRG fillers can release six ions, fluoride $\left(\mathrm{F}^{-}\right)$, sodium $\left(\mathrm{Na}^{+}\right)$, borate $\left(\mathrm{BO}_{3}{ }^{3-}\right)$, aluminium $\left(\mathrm{Al}^{3+}\right)$, silicate $\left(\mathrm{SiO}_{3}{ }^{2-}\right)$, and strontium $\left(\mathrm{Sr}^{2+}\right)$, which have antimicrobial activity against various oral bacteria ${ }^{10}$. Although antimicrobial activity of S-PRG fillers against $S$. mutans has been reported ${ }^{11-13}$, the detailed inhibition mechanisms of S-PRG fillers remain unknown.

Dental caries development caused by $S$. mutans is induced by bacterial growth, survival and adhesion resulting in biofilm formation by microbial communities ${ }^{14}$. Sugar metabolism is an important factor for $S$. mutans growth and survival ${ }^{15,16}$, which is induced via the Embden-Meyerhof-Parnas pathway ${ }^{16}$. The sugar metabolic pathways including the Embden-Meyerhof-Parnas pathway are mainly observed in S. mutans during growth rather than in the stationary phase ${ }^{17}$.

In the present study, we investigated whether a S-PRG eluate prepared with a S-PRG filler can inhibit the bacterial growth of $S$. mutans. In addition, a molecular biological approach focusing on alterations in S. mutans

Department of Pediatric Dentistry, Division of Oral Infections and Disease Control, Osaka University Graduate School of Dentistry, Suita, Osaka, Japan. Correspondence and requests for materials should be addressed to R.N. (email: rnomura@dent.osaka-u.ac.jp) 
gene expression in the presence of S-PRG eluate was performed using DNA microarray analysis. Furthermore, we analysed the inhibitory effects of the S-PRG eluate on several in vitro properties of $S$. mutans relavent to the development of dental caries.

\section{Results}

Inhibitory effects of S-PRG eluate on bacterial growth. S-PRG eluate was added at final concentrations of $0 \%, 6.3 \%, 12.5 \%$ and $25.0 \%$ in brain heart infusion (BHI) broth (Difco Laboratories, Detroit, MI, USA). Bacterial suspensions were adjusted in the BHI broth with or without S-PRG eluate at final concentrations ranging from $1.0 \times 10^{3}$ to $1.0 \times 10^{8} \mathrm{CFU} / \mathrm{ml}$. After 18 -h incubation at $37^{\circ} \mathrm{C}$, bacterial growth was measured at $\mathrm{OD}_{550}$ and bacterial suspensions were then streaked onto Mitis Salivarius agar plates (Difco Laboratories) containing bacitracin ( $0.2 \mathrm{U} / \mathrm{ml}$; Sigma-Aldrich, St. Louis, MO, USA) and 15\% (w/v) sucrose (MSB agar), which were anaerobically cultured at $37^{\circ} \mathrm{C}$ for $48 \mathrm{~h}$. S-PRG eluate added to bacterial suspensions $\left(1.0 \times 10^{3}\right.$ to $1.0 \times 10^{5} \mathrm{CFU} /$ $\mathrm{ml}$ in BHI broth) prominently inhibited bacterial growth, even after incubation at $37^{\circ} \mathrm{C}$ for $18 \mathrm{~h}$. This inhibition was S-PRG-concentration-dependent for both $\mathrm{OD}_{550}$ densities and bacterial numbers (Fig. 1A,B). Although slightly lower $\mathrm{OD}_{550}$ values were observed in bacterial suspensions with concentrations ranging from $1.0 \times 10^{6}$ to $1.0 \times 10^{8} \mathrm{CFU} / \mathrm{ml}$, the test strains at concentrations $>1.0 \times 10^{6} \mathrm{CFU} / \mathrm{ml}$ did not show extensive reduction in cell numbers even when the S-PRG eluate was added at high concentrations. Thus, test strains adjusted to a final density of $1.0 \times 10^{7} \mathrm{CFU} / \mathrm{ml}$ were not growth inhibited even in the presence of $25 \%$ of S-PRG eluate after 18 -h incubation at $37^{\circ} \mathrm{C}$ and were mainly used in subsequent studies. Next, we monitored the kinetics of growth inhibition of $1.0 \times 10^{7} \mathrm{CFU} / \mathrm{ml}$ S. mutans in the presence of each concentration of S-PRG eluate before reaching the stationary phase. Bacterial growth of S. mutans without S-PRG eluate reached a plateau 7-h after incubation, and the lag times were lengthened in a dose dependent manner with the S-PRG eluate (Fig. 1C). The lag time for $S$. mutans to reach the stationary phase in the presence of $25 \%$ S-PRG eluate was approximately twice that in the absence of the S-PRG eluate. Furthermore, survival of $1.0 \times 10^{7} \mathrm{CFU} / \mathrm{ml} \mathrm{S}$. mutans in the presence of each concentration of S-PRG eluate after the stationary phase was monitored (Fig. 1D). The recovered bacterial numbers were not different among $S$. mutans in the presence of each concentration of S-PRG eluate after two days of incubation. However, the numbers of recovered S. mutans were reduced in a dose dependent manner with the S-PRG eluate and no bacteria were recovered in the presence of $25 \%$ S-PRG eluate 10 days after incubation.

DNA microarray assays. The S-PRG eluate could delay bacterial growth and inhibit bacterial survival of $1.0 \times 10^{7} \mathrm{CFU} / \mathrm{ml}$ S. mutans; thus, we decided to identify key genes of S. mutans affected by the S-PRG eluate. $1.0 \times 10^{7} \mathrm{CFU} / \mathrm{ml}$ of $S$. mutans MT8148 and UA159 in BHI broth were cultured with each specified concentration of S-PRG eluate at $37^{\circ} \mathrm{C}$ for $18 \mathrm{~h}$. Next, RNA samples were extracted from each sample for microarray analysis. In the microarray analysis, we evaluated three conditions at several concentrations of S-PRG eluate: $0 \%$ versus $6.3 \%, 0 \%$ versus $12.5 \%$, and $0 \%$ versus $25.0 \%$. From a list of genes, we selected those with increased or decreased changes of greater than 1.0 of $\log 2$ ratio for comparison. First, we identified genes prominently regulated under all three conditions, which were identified in both S. mutans MT8148 and UA159, to reduce confounding effects of false signals (Fig. 2A). DNA microarray analysis revealed that eight genes were downregulated in all comparisons (Tables 1, 2). Among these genes, genes encoding the pyruvate dehydrogenase (PDH) complex, which plays an important role in $S$. mutans survival and is closely related to sugar metabolism ${ }^{15,18}$, were prominently downregulated. The PDH complex forms an operon containing four genes, $p d h D, p d h A, p d h B$, and $p d h C^{15}$, all of which were downregulated by S-PRG eluate in a concentration-dependent manner in both MT8148 and UA159 (Fig. 2B).

We also performed DNA microarray analyses under two different conditions focusing on S-PRG eluate concentrations of $0 \%$ versus $12.5 \%$ and $0 \%$ versus $25.0 \%$ (Fig. $3 \mathrm{~A}$ ), which revealed that nine genes were downregulated in both MT8148 and UA159 (Tables 3, 4). Among the downregulated genes, four genes encoding the putative glycogen synthase, named $g \lg A, g \lg B, g \lg C$, and $g \lg \mathrm{D}^{19}$, were downregulated by S-PRG eluate in a concentration-dependent manner (Fig. 3B). These genes are involved in glycogen synthesis and the glycogen produced is used for $S$. mutans survival under sugar-starved conditions ${ }^{19,20}$. We further analysed genes prominently regulated under the three conditions at several concentrations of S-PRG eluate: $6.3 \%, 12.5 \%$, and $25.0 \%$, which were identified in either MT8148 or UA159 (Fig. 4A). Among the 40 genes identified ( 8 and 32 genes identified in MT8148 and UA159, respectively) (Tables 5, 6), the lac operon (lacA, lacB, lacC, lacD, lacE, lacF, lacG), which is involved in galactose and lactose metabolism in $S$. mutans ${ }^{21}$, was prominently downregulated in UA159 in a concentration-dependent manner (Fig. 4B). Although the com Y operon (com YA, com YB, com YC, com YD), which is associated with quorum sensing and biofilm formation ${ }^{22,23}$, was downregulated in UA159, the signals and inhibition of the com $Y$ operon were less prominent when compared to other operons.

No genes were upregulated in both MT8148 and UA159 under all three eluate conditions tested. DNA microarray analysis employing two different eluate concentrations (Supplemental Fig. 1A) showed only two genes were upregulated with lower fold changes in both MT8148 and UA159 (Supplemental Tables 1 and 2). We further identified six genes in either MT8148 or UA159 under the three different conditions tested (Supplemental Fig. 1B). However, these changes in expressions for all of the genes were relatively small (Supplemental Tables 3 and 4).

Inhibitory effects of S-PRG eluate in in vitro sucrose-dependent adhesion. Bacterial suspensions were adjusted in BHI broth containing $1 \%$ sucrose to a final concentration of $1.0 \times 10^{7} \mathrm{CFU} / \mathrm{ml} \mathrm{S}$. mutans with or without S-PRG eluate. The bacterial suspensions were then cultured at $37^{\circ} \mathrm{C}$ for $18 \mathrm{~h}$ at a $30^{\circ}$ angle and sucrose-dependent adhesion analysis was performed as previously described ${ }^{24}$. Before the analysis, we confirmed that there were no differences in the total bacterial numbers tested (adhesive cells and non-adhesive cells) in the 

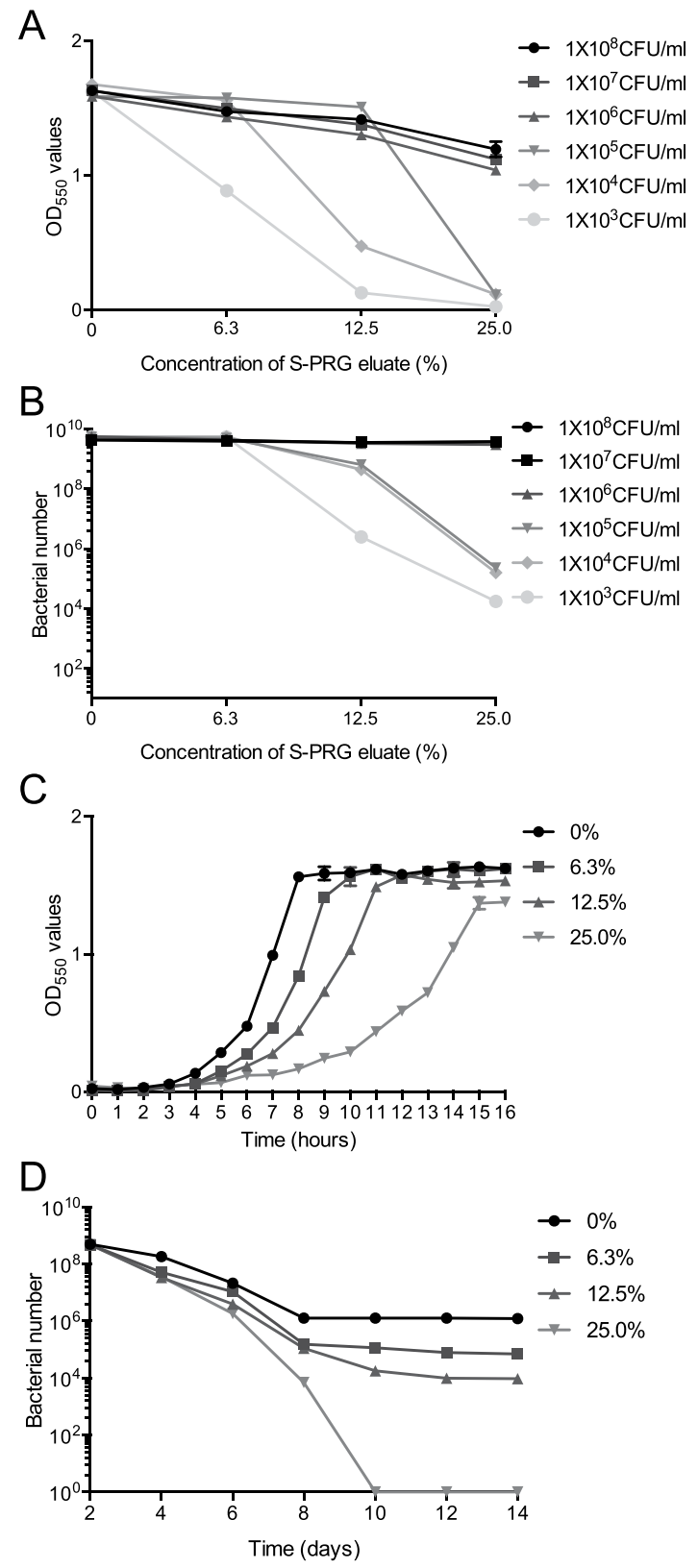

Figure 1. Inhibition on S. mutans MT8148 grown by the S-PRG eluate. (A,B) Bacterial growth by adding varying concentration of the eluate followed by $18 \mathrm{~h}$ incubation. Growth was determined by $\mathrm{OD}_{550}$ values in BHI broth (A) and recovered bacterial numbers on MSB plates (B). (C) Bacterial growth by adding $1 \times 10^{7} \mathrm{CFU} / \mathrm{ml}$ of $S$. mutans at multiple time points, which was determined by $\mathrm{OD}_{550}$ values in $\mathrm{BHI}$ broth. (D) Bacterial survival by adding $1 \times 10^{7} \mathrm{CFU} / \mathrm{ml}$ of $S$. mutans at multiple time points, which was determined by adding serial dilutions of the bacterial suspensions to MSB plates.

cultured bacteria among various concentration of S-PRG eluate (Fig. 5A,B). S-PRG eluate significantly inhibited sucrose-dependent adhesion of $S$. mutans in a concentration-dependent manner $(P<0.05)$ (Fig. 5C).

Inhibitory effects of S-PRG eluate on biofilm formation. Bacterial suspensions were adjusted in BHI broth containing $0 \%, 0.25 \%$ and $1 \%$ sucrose to a final concentration of $1.0 \times 10^{7} \mathrm{CFU} / \mathrm{ml} \mathrm{S.} \mathrm{mutans}$ in the presence or absence of S-PRG eluate. The bacterial suspensions were then added to saliva coated 96-well polystyrene microtiter plates. After incubation at $37^{\circ} \mathrm{C}$ for $24 \mathrm{~h}$, biofilms were quantified following staining with crystal violet and the structures of the biofilms were observed by confocal laser scanning microscopy. The quantity of formed biofilms was similar in BHI broth containing $0.25 \%$ and $1 \%$ sucrose, which were drastically reduced even at a low concentration of S-PRG eluate (Fig. 6A,B, Supplemental Fig. 2A). Both biofilm density and thickness were significantly reduced in the presence of S-PRG eluate, with significant differences $(P<0.001)$ (Fig. 6C,D). On the 
A

MT8148

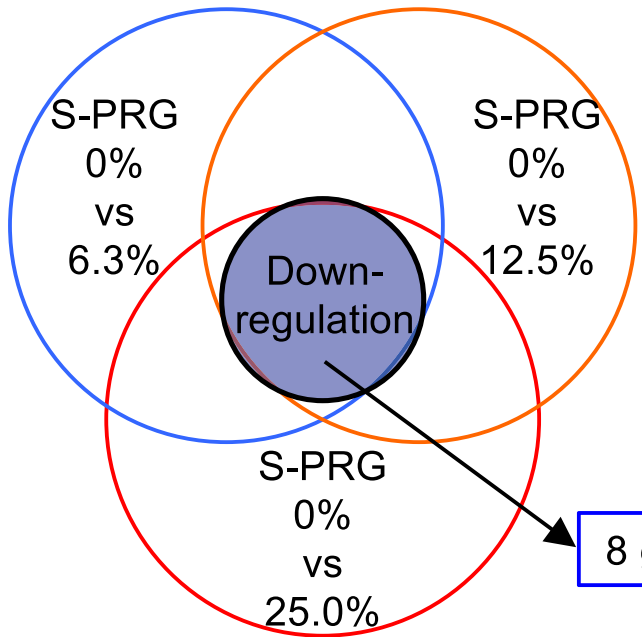

UA159

B
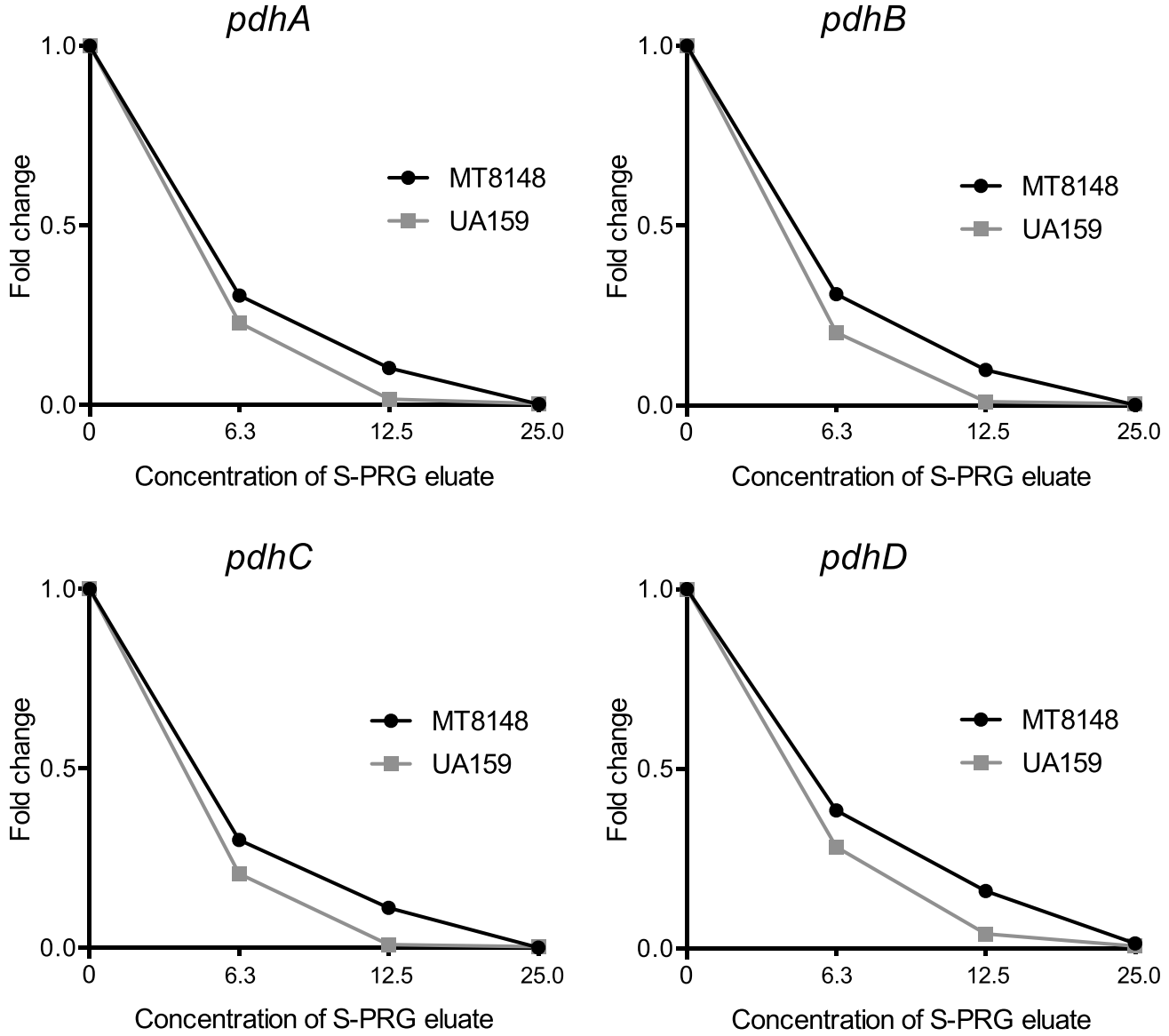

Figure 2. Altered expression of key genes in both S. mutans MT8148 and UA159 under three different conditions using DNA microarray analysis. (A) Detection of altered genes in the presence of S-PRG eluate. (B) Changes in the expression of genes in the $p d h$ operon of MT8148 and UA159 in the presence of S-PRG eluate.

other hand, only weak biofilms were observed in the absence of sucrose regardless of the presence or absence of S-PRG eluate (Supplemental Fig. 2B).

Inhibitory effects of S-PRG eluate on cellular hydrophobicity. Hydrophobic interactions involving $S$. mutans and tooth surfaces play a major role in the sucrose-independent initial adhesion of $S$. mutans to teeth ${ }^{25}$. 


\begin{tabular}{|c|c|c|c|c|c|c|c|c|c|c|c|}
\hline \multirow[b]{2}{*}{ Gene } & \multirow{2}{*}{$\begin{array}{l}\text { Accession } \\
\text { number }\end{array}$} & \multirow{2}{*}{\begin{tabular}{|l|} 
S-PRG 0\% \\
Signal
\end{tabular}} & \multicolumn{3}{|c|}{ S-PRG 6.3\% $\%$} & \multicolumn{3}{|c|}{ S-PRG12.5 } & \multicolumn{3}{|c|}{ S-PRG 25.0\% } \\
\hline & & & Signal & $\log 2 *$ & Change\# & Signal & $\log 2 *$ & Change $^{*}$ & \begin{tabular}{|l|} 
Signal \\
\end{tabular} & $\log 2 *$ & Change\# \\
\hline$c l p$ & \begin{tabular}{|l|}
721354.1 \\
\end{tabular} & 10905.7 & 3934.7 & -1.47 & 0.361 & 2604.3 & -2.07 & 0.239 & 779.1 & -3.81 & 0.071 \\
\hline gldA & \begin{tabular}{|l|l|}
720934.1 \\
\end{tabular} & 79738.3 & 15155.0 & -2.40 & 0.190 & 4829.4 & -4.04 & 0.061 & 2716.1 & -4.88 & 0.034 \\
\hline$p d h A$ & \begin{tabular}{|l|}
721781.1 \\
\end{tabular} & \begin{tabular}{|l|}
157937.7 \\
\end{tabular} & 49355.6 & -1.68 & 0.312 & \begin{tabular}{|l|}
17366.4 \\
\end{tabular} & -3.19 & 0.110 & 451.1 & -8.45 & 0.003 \\
\hline$p d h B$ & \begin{tabular}{|l|l|}
721780.1 \\
\end{tabular} & 118457.0 & 38021.4 & -1.64 & 0.321 & 12313.0 & -3.26 & 0.104 & 232.9 & -9.05 & 0.002 \\
\hline$p d h C$ & \begin{tabular}{|l|}
721779.1 \\
\end{tabular} & \begin{tabular}{|l|}
147220.0 \\
\end{tabular} & 47212.9 & -1.64 & 0.321 & 17231.7 & -3.09 & 0.117 & 205.2 & -9.49 & 0.001 \\
\hline$p d h D$ & \begin{tabular}{|l|}
721782.1 \\
\end{tabular} & 20637.6 & 8184.3 & -1.33 & 0.397 & 3493.2 & -2.56 & 0.169 & 332.1 & -5.98 & 0.016 \\
\hline$p f l 2$ & \begin{tabular}{|l|}
720932.1 \\
\end{tabular} & 16001.1 & 5582.2 & -1.52 & 0.349 & 3688.0 & -2.12 & 0.231 & 798.1 & -4.33 & 0.050 \\
\hline$p h s G$ & 721879.1 & 36063.9 & 13506.8 & -1.42 & 0.375 & 6031.0 & -2.58 & 0.167 & 1521.6 & -4.57 & 0.042 \\
\hline
\end{tabular}

Table 1. List of downregulated genes of MT8148 in the presence of S-PRG eluate, which were observed in both MT8148 and UA159 under three different conditions using DNA microarray analysis. ${ }^{*} \log 2$ means Log2 ratio. \#Change means Fold change. The Log2 ratio and Fold change were calculated by signal in each concentration of S-PRG eluate/signal without S-PRG eluate.

\begin{tabular}{|c|c|c|c|c|c|c|c|c|c|c|c|}
\hline \multirow[b]{2}{*}{ Gene } & \multirow{2}{*}{$\begin{array}{l}\text { Accession } \\
\text { number }\end{array}$} & \multirow{2}{*}{\begin{tabular}{|l|}
$\begin{array}{l}\text { S-PRG } \\
\mathbf{0} \%\end{array}$ \\
Signal \\
\end{tabular}} & \multicolumn{3}{|c|}{ S-PRG 6.3\% } & \multicolumn{3}{|c|}{ S-PRG12.5\% } & \multicolumn{3}{|c|}{ S-PRG 25.0\% } \\
\hline & & & Signal & $\log 2 *$ & Change\# & Signal & $\log 2^{*}$ & Change $^{\#}$ & Signal & $\log 2^{*}$ & Change\# \\
\hline$c l p$ & \begin{tabular}{|l|}
721354.1 \\
\end{tabular} & 18865.6 & 6619.2 & -1.51 & 0.351 & 2873.2 & -2.71 & 0.152 & 3817.9 & -2.30 & 0.202 \\
\hline gldA & \begin{tabular}{|l|}
720934.1 \\
\end{tabular} & 55312.5 & 21392.5 & -1.37 & 0.387 & 9103.4 & -2.60 & 0.165 & 2217.9 & -4.64 & 0.040 \\
\hline$p d h A$ & \begin{tabular}{|l|}
721781.1 \\
\end{tabular} & \begin{tabular}{|l|}
30983.4 \\
\end{tabular} & 7458.1 & -2.06 & 0.241 & 547.5 & -5.82 & \begin{tabular}{|l|}
0.018 \\
\end{tabular} & 151.5 & -7.68 & 0.005 \\
\hline$p d h B$ & \begin{tabular}{|l|}
721780.1 \\
\end{tabular} & 26341.2 & 5687.7 & -2.21 & 0.216 & 283.9 & -6.53 & 0.011 & 131.4 & -7.69 & 0.005 \\
\hline$p d h C$ & \begin{tabular}{|l|}
721779.1 \\
\end{tabular} & \begin{tabular}{|l|}
32996.4 \\
\end{tabular} & 7188.0 & -2.20 & 0.218 & 320.5 & -6.69 & 0.010 & 128.0 & -8.01 & 0.004 \\
\hline$p d h D$ & \begin{tabular}{|l|}
721782.1 \\
\end{tabular} & 5817.6 & 1717.4 & -1.76 & \begin{tabular}{|l|}
0.295 \\
\end{tabular} & 250.6 & -4.54 & 0.043 & 47.4 & -6.95 & 0.008 \\
\hline$p f l 2$ & \begin{tabular}{|l|}
720932.1 \\
\end{tabular} & 11402.1 & 3593.0 & -1.67 & 0.315 & 2135.1 & -2.42 & 0.187 & 1288.9 & -3.14 & 0.113 \\
\hline$p h s G$ & \begin{tabular}{|l|}
721879.1 \\
\end{tabular} & 41481.6 & \begin{tabular}{|l|}
17147.4 \\
\end{tabular} & -1.27 & 0.413 & 8112.9 & -2.35 & \begin{tabular}{|l|}
0.196 \\
\end{tabular} & 1380.1 & -4.91 & 0.033 \\
\hline
\end{tabular}

Table 2. List of downregulated genes of UA159 in the presence of S-PRG eluate, which were observed in both MT8148 and UA159 under three different conditions using DNA microarray analysis. ${ }^{*} \log 2$ means Log2 ratio. \#Change means Fold change. The Log2 ratio and Fold change were calculated by signal with each concentration of S-PRG eluate/signal without S-PRG eluate.

We determined whether the S-PRG eluate inhibited the hydrophobic properties of S. mutans using an in vitro cellular hydrophobicity assay, which was assessed by the hydrophobic interaction of $S$. mutans and n-hexadecane ${ }^{26}$. A mixture of each concentration of S-PRG eluate and bacterial cultures adjusted to $\mathrm{OD}_{550}$ of 0.6 was vigorously vortexed for $1 \mathrm{~min}$ in the presence of $\mathrm{n}$-hexadecane to induce hydrophobic interaction between $\mathrm{n}$-hexadecane and the test strain. Cellular hydrophobicity rates were assessed via $n$-hexadecane partitioning by $S$. mutans in the presence of various concentrations of S-PRG eluate and showed no significant differences (Fig. 7A). Next, to examine the effects of incubation time on such interactions, we further analysed cellular hydrophobicity using $S$. mutans cells pretreated with S-PRG eluate for $18 \mathrm{~h}$. The S-PRG eluate did not affect bacterial numbers (Fig. 7B), and significantly inhibited cellular hydrophobicity $(P<0.05, P<0.01)$ (Fig. 7C).

Inhibitory effects of S-PRG eluate against S. mutans in post-logarithmic phase. Bacteria in the stationary phase exhibit low sugar metabolic activity ${ }^{17}$. Thus, we investigated the effects of S-PRG eluate on bacterial growth, sucrose-dependent adhesion and biofilm formation using post-logarithmic phase $1.0 \times 10^{9} \mathrm{CFU} /$ $\mathrm{ml}$ of $S$. mutans. Bacterial numbers were not affected by S-PRG eluate after 18 -h incubation although the $\mathrm{OD}_{550}$ densities were lower at the higher concentrations of S-PRG eluate in a dose dependent manner (Fig. 8A,B). In addition, bacterial growth in the presence of each S-PRG eluate was monitored and reached the stationary phase within 3-h after incubation (Fig. 8C). Although sucrose-dependent adhesion and biofilm formation by S. mutans in the post-logarithmic phase were inhibited in the presence of S-PRG eluate, the inhibitory effects were not as prominent as those using $1.0 \times 10^{7} \mathrm{CFU} / \mathrm{ml}$ of $S$. mutans prior to the logarithmic growth phase (Fig. $\left.8 \mathrm{D}, \mathrm{E}\right)$.

Inhibitory effects of S-PRG eluate against other streptococci. S-PRG eluate prominently repressed the expression of genes encoding the pyruvate dehydrogenase $(\mathrm{PDH})$ complex, and the complex is known to be important for bacterial growth and survival ${ }^{27}$. Thus, we analyzed the inhibitory effect of S-PRG eluate against other oral streptococci using two different types of oral streptococcal species; Streptococcus sobrinus B13 which is a S. mutans-related species with sucrose-dependent cariogenic properties ${ }^{28}$, and Streptococcus gordonii ATCC10558 lacking sucrose-dependent cariogenic properties ${ }^{29}$. S. sobrinus before reaching the logarithmic phase (adjusted to $1 \times 10^{5} \mathrm{CFU} / \mathrm{ml}$ ) was inhibited by S-PRG eluate in a concentration-dependent manner (Fig. 9A), whereas inhibition was not observed using the bacteria in the post-logarithmic phase (adjusted to $1 \times 10^{9} \mathrm{CFU} / \mathrm{ml}$ ) (Fig. 9B), similar to what was observed with S. mutans. The inhibitory effect on S. gordonii in the presence of S-PRG eluate was observed only with the bacterium before reaching the logarithmic growth phase (adjusted to $1 \times 10^{5} \mathrm{CFU} /$ 
A

MT8148

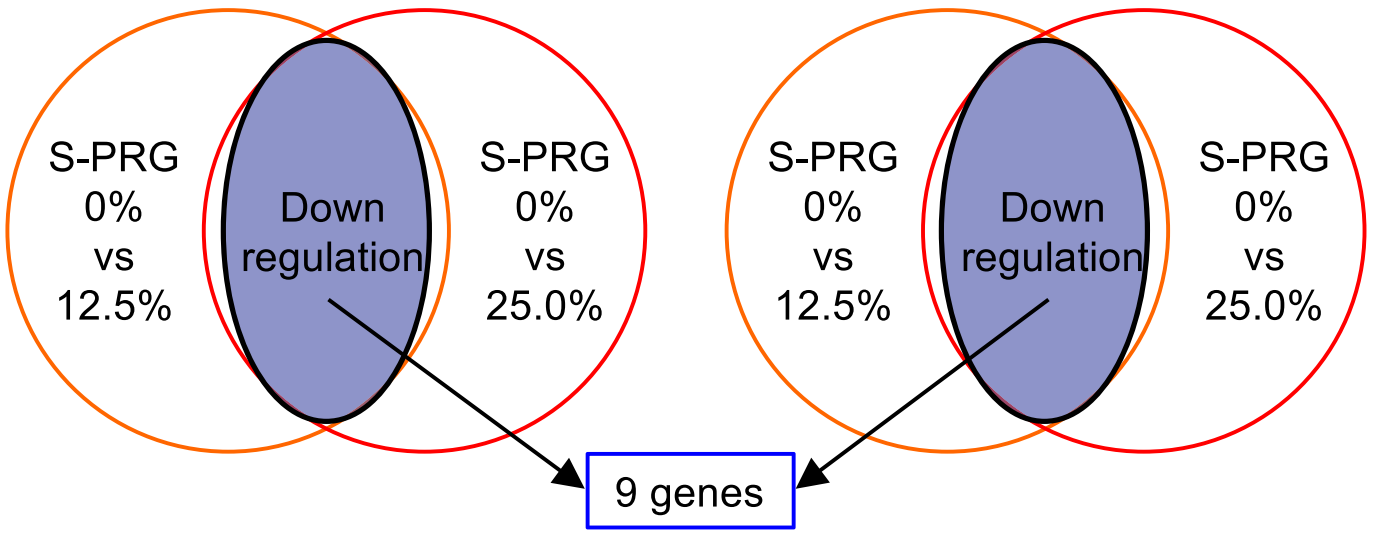

B
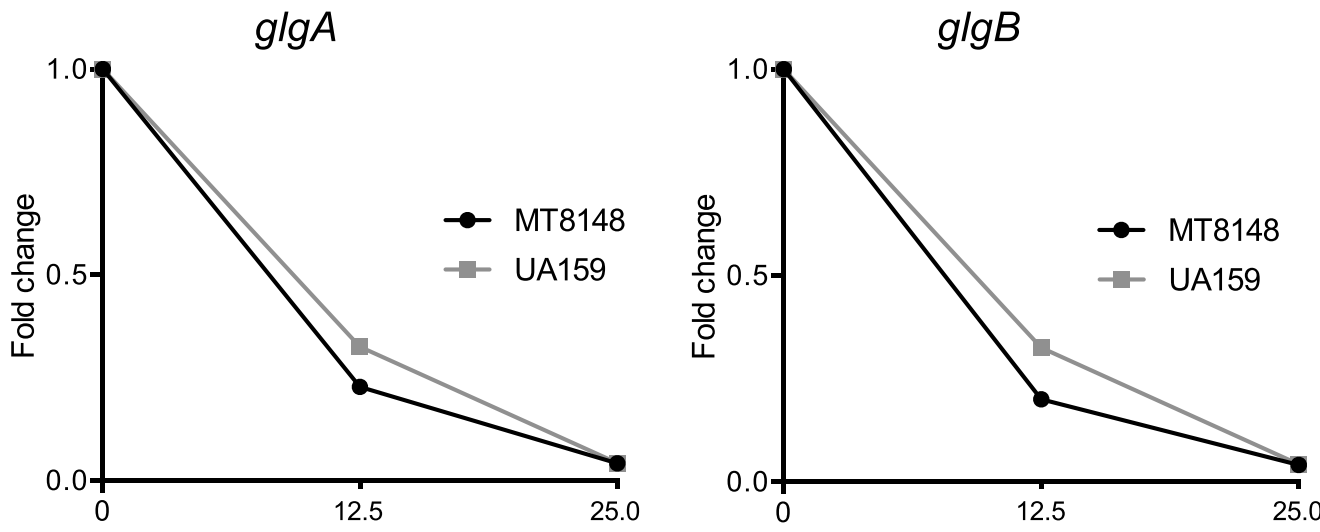

Concentration of S-PRG eluate

Concentration of S-PRG eluate

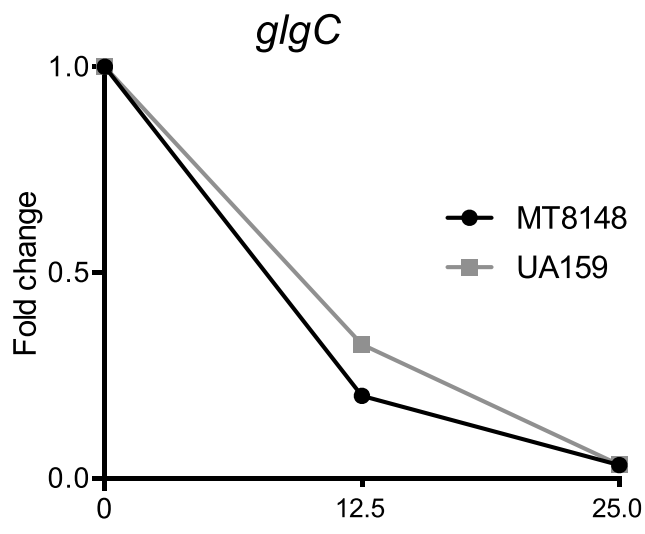

Concentration of S-PRG eluate

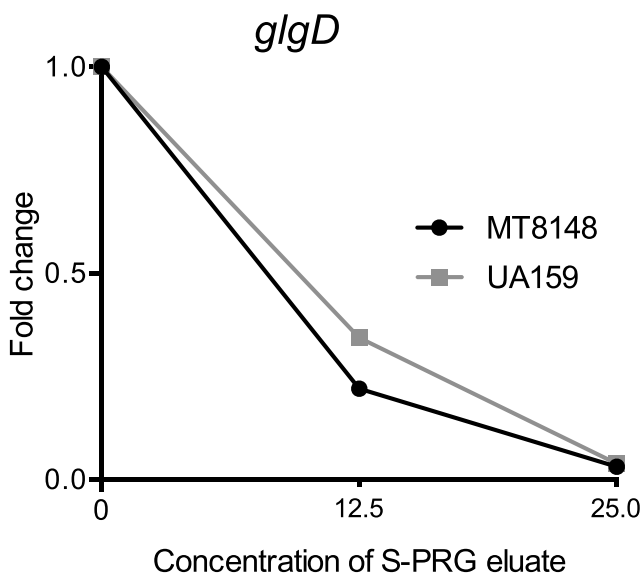

Figure 3. Altered expression of key genes in both S. mutans MT8148 and UA159 under two different conditions detected by DNA microarray analysis. (A) Detection of altered genes in the presence of S-PRG eluate. (B) Changes in the expression of genes in the $g l g$ operon of MT8148 and UA159 in the presence of S-PRG eluate.

$\mathrm{ml}$ ), though the inhibitory effect was lower than that observed in S. mutans and S. sobrinus (Fig. 9C,D). In addition, the S-PRG eluate significantly inhibited sucrose-dependent adhesion and biofilm formation by S. sobrinus before reaching the logarithmic growth phase (adjusted to $\left.1 \times 10^{7} \mathrm{CFU} / \mathrm{ml}\right)(P<0.05)($ Fig. 9E-H).

\section{Discussion}

Recent studies showed that a S-PRG filler could inhibit the growth and adherence of $S$. mutans ${ }^{12,13}$. However, these studies were performed for the purpose of developing dental products containing S-PRG filler, and not necessarily for antimicrobial activity. In the present study, we analysed the inhibitory effects of S-PRG eluate against 


\begin{tabular}{|c|c|c|c|c|c|c|c|c|c|c|c|}
\hline \multirow[b]{2}{*}{ Gene } & \multirow{2}{*}{$\begin{array}{l}\text { Accession } \\
\text { number }\end{array}$} & \multirow{2}{*}{\begin{tabular}{|l|} 
S-PRG 0\% \\
Signal \\
\end{tabular}} & \multicolumn{3}{|c|}{ S-PRG 6.3\% } & \multicolumn{3}{|c|}{ S-PRG12.5\% } & \multicolumn{3}{|c|}{ S-PRG 25.0\% } \\
\hline & & & Signal & $\log 2 *$ & Change $^{*}$ & Signal & $\log 2 *$ & Change $^{*}$ & Signal & $\log 2 *$ & Change $^{*}$ \\
\hline$c e l R$ & 721935.1 & 34392.8 & 18718.7 & -0.88 & 0.545 & 7975.4 & -2.11 & 0.232 & 11089.6 & -1.63 & 0.323 \\
\hline$g \lg A$ & \begin{tabular}{|l|}
721880.1 \\
\end{tabular} & 44037.6 & 25098.8 & -0.81 & 0.570 & 10246.4 & -2.10 & 0.233 & 1907.0 & -4.53 & 0.043 \\
\hline$g \lg B$ & \begin{tabular}{|l|}
721883.1 \\
\end{tabular} & 29635.1 & 20348.1 & -0.54 & 0.687 & 6239.4 & -2.25 & 0.211 & 1451.3 & -4.35 & 0.049 \\
\hline$g \operatorname{lgC}$ & \begin{tabular}{|l|l|}
721882.1 \\
\end{tabular} & 45034.7 & 29677.1 & -0.60 & 0.659 & 9715.7 & -2.21 & 0.215 & 1516.4 & -4.89 & 0.034 \\
\hline$g l g D$ & \begin{tabular}{|l|}
721881.1 \\
\end{tabular} & 210544.6 & 147984.5 & -0.51 & 0.703 & 48733.9 & -2.11 & 0.231 & 6864.6 & -4.94 & 0.033 \\
\hline$p f l$ & \begin{tabular}{|l|l|}
720850.1 \\
\end{tabular} & \begin{tabular}{|l|}
200380.8 \\
\end{tabular} & 202526.0 & 0.02 & 1.011 & 36209.8 & -2.47 & 0.181 & 24825.3 & -3.01 & 0.124 \\
\hline$p t c A$ & \begin{tabular}{|l|}
721934.1 \\
\end{tabular} & 21838.2 & 12188.5 & -0.84 & 0.558 & 4817.3 & -2.18 & 0.221 & 6571.4 & -1.73 & 0.301 \\
\hline$p t c C$ & \begin{tabular}{|l|}
721932.1 \\
\end{tabular} & 8470.6 & 4527.1 & -0.90 & 0.534 & 2615.5 & -1.70 & 0.309 & 2737.8 & -1.63 & 0.323 \\
\hline wapA & 721382.1 & 3431.3 & 1740.2 & -0.98 & 0.507 & 1588.4 & -1.11 & 0.463 & 1652.3 & -1.05 & 0.482 \\
\hline
\end{tabular}

Table 3. List of downregulated genes of MT8148 in the presence of S-PRG eluate, which were observed in both MT8148 and UA159 under two different conditions using DNA microarray analysis. ${ }^{*} \log 2$ means $\log 2$ ratio. \#Change means Fold change. The Log2 ratio and Fold change were calculated by signal with each concentration of S-PRG eluate/signal without S-PRG eluate.

\begin{tabular}{|c|c|c|c|c|c|c|c|c|c|c|c|}
\hline \multirow[b]{2}{*}{ Gene } & \multirow{2}{*}{$\begin{array}{l}\text { Accession } \\
\text { number }\end{array}$} & \multirow{2}{*}{\begin{tabular}{|l|} 
S-PRG 0\% \\
Signal
\end{tabular}} & \multicolumn{3}{|c|}{ S-PRG 6.3\% } & \multicolumn{3}{|c|}{ S-PRG12.5\% } & \multicolumn{3}{|c|}{ S-PRG 25.0\% } \\
\hline & & & Signal & $\log 2^{*}$ & Change $^{*}$ & Signal & $\log 2^{*}$ & Change $^{*}$ & Signal & $\log 2^{*}$ & Change $^{*}$ \\
\hline celR & 721935.1 & 11936.0 & 1137.1 & -3.39 & 0.095 & 366.9 & -5.02 & 0.031 & 38.4 & -8.30 & 0.003 \\
\hline $\operatorname{glg} A$ & 721880.1 & 30585.2 & 17989.6 & -0.77 & 0.588 & 10161.1 & -1.59 & 0.332 & \begin{tabular}{|l|}
1366.7 \\
\end{tabular} & -4.48 & 0.045 \\
\hline $\operatorname{glg} B$ & 721883.1 & 18468.0 & 16127.7 & -0.20 & 0.873 & 8708.1 & -1.08 & 0.471 & 932.6 & -4.31 & 0.050 \\
\hline$g l g C$ & 721882.1 & 30765.2 & 23441.6 & -0.39 & 0.762 & 10508.8 & -1.55 & \begin{tabular}{|l|}
0.342 \\
\end{tabular} & 1055.7 & -4.87 & \begin{tabular}{|l|}
0.034 \\
\end{tabular} \\
\hline$g \lg D$ & 721881.1 & 134094.9 & 101989.3 & -0.39 & 0.761 & 48072.9 & -1.48 & 0.359 & 5395.6 & -4.64 & 0.040 \\
\hline$p f l$ & 720850.1 & 210979.6 & \begin{tabular}{|l|}
166145.4 \\
\end{tabular} & -0.35 & 0.787 & \begin{tabular}{|l|}
69347.0 \\
\end{tabular} & -1.61 & 0.329 & 9805.4 & -4.43 & 0.046 \\
\hline$p t c A$ & 721934.1 & 7508.6 & 633.3 & -3.57 & 0.084 & 207.5 & -5.19 & \begin{tabular}{|l|}
0.027 \\
\end{tabular} & 17.7 & -8.74 & \begin{tabular}{|l|}
0.002 \\
\end{tabular} \\
\hline$p t c C$ & 721932.1 & 2921.0 & 366.2 & -3.00 & 0.125 & 124.6 & -4.56 & 0.043 & 38.5 & -6.25 & 0.013 \\
\hline wapA & 721382.1 & 3891.4 & 2323.7 & -0.76 & 0.590 & 1931.4 & -1.01 & 0.496 & 568.7 & -2.77 & 0.146 \\
\hline
\end{tabular}

Table 4. List of downregulated genes of UA159 in the presence of S-PRG eluate, which were observed in both MT8148 and UA159 under two different conditions using DNA microarray analysis. * Log2 means Log2 ratio.

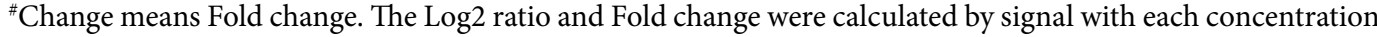
of S-PRG eluate/signal without S-PRG eluate.

S. mutans, focusing on the cariogenic properties and virulence genes of the bacterium, which are closely related to dental caries development.

S-PRG filler has been widely used in dental products, mainly contained in sealant and composite resins ${ }^{7,8}$. Although the effects of the presence of each ion component may be different from that in the presence of the other divalent and trivalent ions, releases of all ions from the S-PRG filler in composite resin could be confirmed even after overnight incubation ${ }^{13}$. In addition, the released ions were also identified in whole saliva ${ }^{12}$. Thus, inhibitory effects similar to those of S-PRG eluate observed in the present study may be expected for dental materials containing S-PRG filler, although the exact amounts of the released ions may be different for each clinical situation.

Multiple ions may affect the biological activity for many bacteria ${ }^{30}$. On the other hand, some of the bacteria such as Psuedomonas aeruginosa have developed a variety of mechanisms to escape the inhibitory effects of the ions. For example, P. aeruginosa can immobilize metal ions outside of the cell, reducing the inhibitory effect of the ions ${ }^{31}$. Conversely, the existence of multiple metal ions sometimes contributes to supporting biofilm formation by bacteria ${ }^{30,32}$. In the present study, a S- PRG eluate could effectively inhibit the growth and in vitro cariogenicity of $S$. mutans. In addition, a previous study showed that all of six ions released from a S- PRG filler could inhibit bacterial growth ${ }^{13}$. However, it was reported that some of the proteins of $S$. mutans encodes metal ion transport systems, which are considered as virulence factors for dental caries and infective endocarditis ${ }^{33,34}$. Therefore, further studies should be performed focusing on how the inhibitory effects against $S$. mutans induced by these ions alter bacterial virulence.

One of the most important factors for growth and survival of $S$. mutans is sugar metabolism. The sugar metabolism induced by $S$. mutans occurs through the Embden-Meyerhof-Parnas pathway, followed by acid production from pyruvate ${ }^{16}$. Inhibition of $S$. mutans growth in the presence of S-PRG eluate may result from interference with the Embden-Meyerhof-Parnas pathway or subsequent acid production pathways. To identify the key $S$. mutans genes closely related to the inhibition of growth and survival of the bacterium in the presence of S-PRG eluate, we performed DNA microarray analysis.

Based upon the results of the microarray analysis, S-PRG eluate appeared to strongly downregulate several S. mutans genes and the downregulation of some genes in the presence of S-PRG eluate was over 100-fold greater than in the absence of the eluate. Conversely, no gene was upregulated by more than 10 -fold in the presence of S-PRG eluate compared with that in the absence of S-PRG eluate. These results indicated that the inhibitory effects on bacterial growth and survival of $S$. mutans in the presence of S-PRG eluate were primarily induced 
A

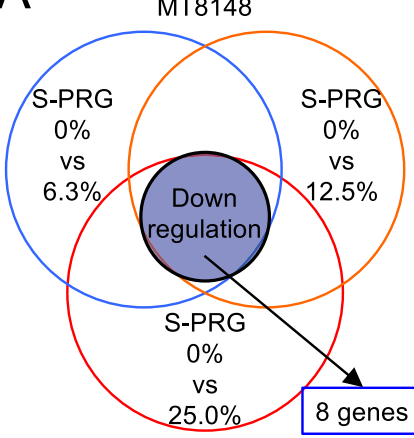

B

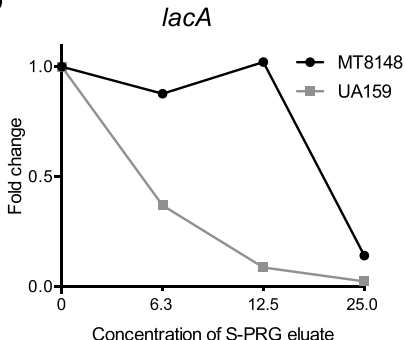

lacC

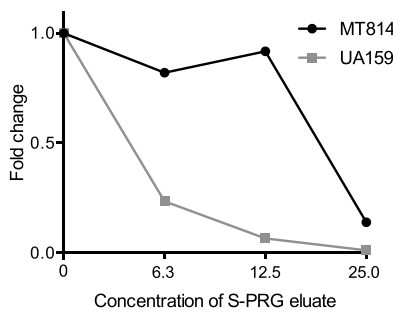

lacE

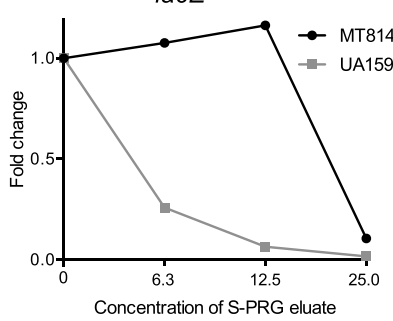

lacG

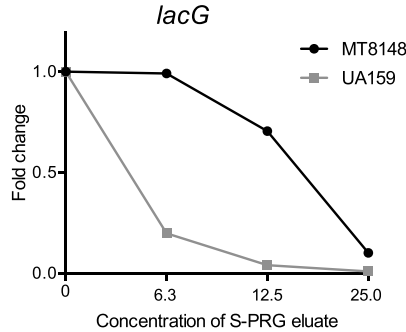

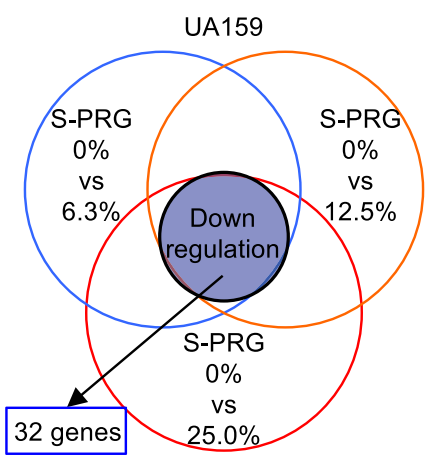

$\operatorname{lac} B$

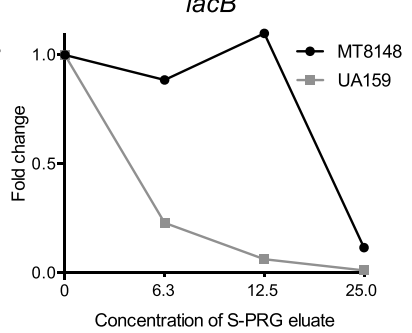

$\operatorname{lac} D$
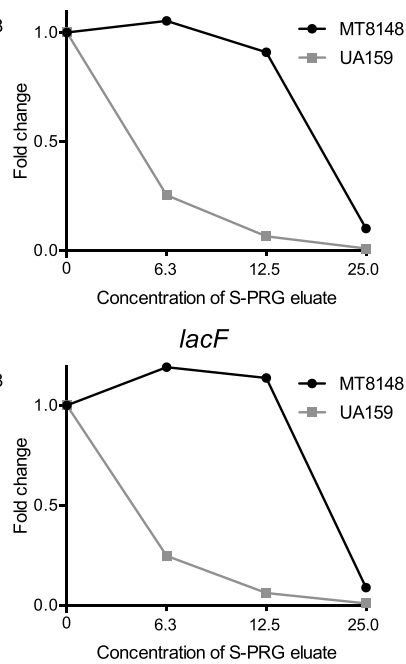

Figure 4. Altered expression of key genes in either S. mutans MT8148 or UA159 under three different conditions using DNA microarray analysis. (A) Detection of altered genes in the presence of S-PRG eluate. (B) Changes in the expression of genes in the lac operon of MT8148 and UA159 in the presence of S-PRG eluate.

by downregulation of several $S$. mutans genes. Interestingly, three operons ( $p d h, g l g$, and lac), all of which play important roles in the survival and sugar metabolism of $S$. mutans, were downregulated in the presence of the S-PRG eluate in a concentration-dependent manner. Thus, these operons may be responsible for the inhibition of bacterial growth and survival observed in the presence of the S-PRG eluate.

Among the genes downregulated by the S-PRG eluate in the DNA microarray analysis, the PDH complex was prominently negatively regulated. The PDH complex converts pyruvate produced following sugar metabolism by $S$. mutans via the Embden-Meyerhof-Parnas pathway to acetyl-CoA and $\mathrm{CO}_{2}{ }^{35}$. The PDH complex is encoded 


\begin{tabular}{|c|c|c|c|c|c|c|c|c|c|c|c|}
\hline \multirow[b]{2}{*}{ Gene } & \multirow{2}{*}{$\begin{array}{l}\text { Accession } \\
\text { number }\end{array}$} & \multirow{2}{*}{\begin{tabular}{|l} 
S-PRG 0\% \\
Signal
\end{tabular}} & \multicolumn{3}{|c|}{ S-PRG 6.3\% } & \multicolumn{3}{|c|}{ S-PRG12.5\% } & \multicolumn{3}{|c|}{ S-PRG 25.0\% } \\
\hline & & & Signal & Log2* & Change $^{\#}$ & Signal & $\log 2^{*}$ & Change $^{*}$ & Signal & $\log 2^{*}$ & Change $^{*}$ \\
\hline$b c c$ & 721410.1 & 3656.2 & 2409.2 & -0.6 & 0.659 & 2386.3 & -0.61 & 0.653 & 1414.7 & -3.81 & \begin{tabular}{|l|}
0.071 \\
\end{tabular} \\
\hline celR & 721935.1 & 34392.8 & 18718.7 & -0.88 & 0.545 & 7975.4 & -2.11 & 0.232 & 11089.6 & -1.63 & 0.323 \\
\hline cilA & 721415.1 & 2407.2 & 1780.9 & -0.43 & 0.741 & 2047.7 & -0.23 & 0.851 & 1084.1 & -1.15 & 0.451 \\
\hline cilB & 721414.1 & 2040.5 & 1377.5 & -0.57 & 0.675 & 1407.6 & -0.53 & 0.69 & 719.7 & -1.5 & 0.353 \\
\hline cilG & 721413.1 & 1982.2 & 1594.2 & -0.31 & 0.804 & 1700.8 & -0.22 & 0.858 & 719.2 & -1.46 & 0.363 \\
\hline citC & 721405.1 & 350.4 & 534.4 & 0.61 & 1.524 & 757.7 & 1.11 & 2.161 & 165.1 & -1.09 & 0.47 \\
\hline$c i t G$ & 721406.1 & 471.1 & 806.7 & 0.78 & 1.713 & 1094.5 & 1.22 & 2.324 & 143.2 & -1.72 & 0.303 \\
\hline citG2 & 721416.1 & 3123.7 & 2413.7 & -0.37 & 0.772 & 2832.3 & -0.14 & 0.907 & 1131.6 & -1.47 & 0.362 \\
\hline coaA & 721513.1 & 186.1 & 250 & 0.43 & 1.344 & 329.3 & 0.82 & 1.767 & 79.9 & -1.22 & 0.429 \\
\hline comEA & 721053.1 & 264.2 & 352.6 & 0.42 & 1.335 & 521.8 & 0.98 & 1.975 & 32.2 & -3.04 & 0.122 \\
\hline comYA & 722285.1 & 151.4 & 221.1 & 0.55 & 1.463 & 343.8 & 1.19 & 2.276 & 22.1 & -2.78 & 0.145 \\
\hline $\operatorname{com} Y B$ & 722284.1 & 253.4 & 374 & 0.56 & 1.479 & 515.5 & 1.03 & 2.042 & 46.4 & -2.44 & 0.184 \\
\hline $\operatorname{com} Y C$ & 722283.1 & 276.9 & 452.1 & 0.71 & 1.635 & 684 & 1.31 & 2.473 & 69 & -2 & 0.249 \\
\hline $\operatorname{com} Y D$ & 722282.1 & 147.2 & 263.5 & 0.85 & 1.801 & 402.7 & 1.45 & 2.724 & 43.7 & -1.76 & 0.295 \\
\hline galR & 721293.1 & 1196.1 & 1062.5 & -0.17 & 0.888 & 1628.9 & 0.44 & 1.36 & 347.9 & -1.78 & 0.291 \\
\hline $\operatorname{grpE}$ & 720560.1 & 24097.8 & 10856.3 & -1.15 & 0.451 & 10952.4 & -1.14 & 0.454 & 3039.2 & -2.99 & 0.126 \\
\hline$h s d M$ & 721299.1 & 103.1 & 17.6 & -2.55 & 0.171 & 14.2 & -2.86 & 0.138 & 40.4 & -1.35 & 0.392 \\
\hline lacA & 721844.1 & 503.8 & 491.8 & -0.04 & 0.975 & 691.5 & 0.46 & 1.371 & 77.4 & -2.71 & 0.153 \\
\hline lacB & 721843.1 & 1420.2 & 1345.4 & -0.08 & 0.947 & 1602.7 & 0.17 & 1.129 & 174.2 & -3.03 & 0.123 \\
\hline lacC & 721842.1 & 693.3 & 681.8 & -0.02 & 0.984 & 733.5 & 0.08 & 1.06 & 104.1 & -2.73 & 0.15 \\
\hline lacD & 721841.1 & 791.7 & 947.8 & 0.24 & 1.184 & 786.9 & -0.01 & 0.994 & 88.4 & -3.16 & 0.112 \\
\hline lacD2 & 720591.1 & 3352.2 & 1741.7 & -0.94 & 0.52 & 1563.4 & -1.1 & 0.466 & 103.9 & -5.01 & 0.031 \\
\hline lacE & 721839.1 & 1851.5 & 2078.7 & 0.17 & 1.124 & 2250.3 & 0.28 & 1.216 & 210.6 & -3.14 & 0.114 \\
\hline lacF & \begin{tabular}{|l|l|}
721840.1 \\
\end{tabular} & 1250.6 & 1567.3 & 0.33 & 1.253 & 1506.8 & 0.27 & 1.205 & 127.4 & -3.3 & 0.102 \\
\hline lacG & \begin{tabular}{|l|l|}
721838.1 \\
\end{tabular} & 7506.5 & 7801.4 & 0.06 & 1.039 & 5603.4 & -0.42 & 0.747 & 783.6 & -3.26 & 0.104 \\
\hline $\operatorname{lac} X$ & 721837.1 & 2089.4 & 2392.3 & 0.19 & 1.143 & 3630.3 & 0.8 & 1.737 & 211.3 & -3.31 & 0.101 \\
\hline lytR & \begin{tabular}{|l|l|}
721011.1 \\
\end{tabular} & 2102.5 & 1188.7 & -0.82 & 0.565 & 1104.9 & -0.93 & 0.526 & 507.7 & -2.05 & 0.241 \\
\hline$o a d B$ & 721411.1 & 4735.5 & 3705.5 & -0.36 & 0.782 & 3979.2 & -0.25 & 0.84 & 2741.2 & -0.79 & 0.578 \\
\hline pflC & 720930.1 & 968.8 & 781.5 & -0.31 & 0.806 & 904.2 & -0.1 & 0.933 & 645 & -0.59 & 0.664 \\
\hline$p t c A$ & \begin{tabular}{|l|l|}
721934.1 \\
\end{tabular} & 21838.2 & 12188.5 & -0.84 & 0.558 & 4817.3 & -2.18 & 0.221 & 6571.4 & -1.73 & 0.301 \\
\hline$p t c B$ & 721936.1 & 1549.5 & 1220.1 & -0.35 & 0.786 & 1351.8 & -0.2 & 0.872 & 1410.3 & -0.14 & 0.91 \\
\hline$p t c C$ & 721932.1 & 8470.6 & 4527.1 & -0.9 & 0.534 & 2615.5 & -1.7 & 0.309 & 2737.8 & -1.63 & 0.323 \\
\hline pycB & 721417.1 & 3315.9 & 2227.8 & -0.57 & 0.672 & 2493.8 & -0.41 & 0.752 & 2372.2 & -0.48 & 0.715 \\
\hline $\operatorname{rgp} G$ & \begin{tabular}{|l|l|}
720710.1 \\
\end{tabular} & \begin{tabular}{|l|}
107407.9 \\
\end{tabular} & 3328.3 & -5.01 & 0.031 & 4296.3 & -4.64 & 0.04 & 4296.3 & -4.64 & 0.04 \\
\hline $\operatorname{scn} E$ & 722129.1 & 47 & 23.3 & -1 & 0.5 & 14.1 & -1.74 & 0.3 & 4.2 & -3.47 & \begin{tabular}{|l|}
0.09 \\
\end{tabular} \\
\hline spaP & 721042.1 & 7581.6 & 3685 & -1.04 & 0.486 & 1858 & -2.03 & 0.245 & 1936 & -1.97 & 0.255 \\
\hline$s s b 2$ & 722266.1 & 673.6 & 980.5 & 0.54 & 1.459 & 1165.4 & 0.79 & 1.733 & 529 & -0.35 & 0.787 \\
\hline trk & 721902.1 & 29059.7 & 13948.7 & -1.06 & 0.48 & 6713.2 & -2.11 & 0.231 & 5386.5 & -2.43 & 0.185 \\
\hline trkB & 721901.1 & 21115.7 & 10376.4 & -1.03 & 0.491 & 4014.8 & -2.4 & 0.19 & 3970.1 & -2.41 & 0.188 \\
\hline wapA & \begin{tabular}{|l|}
721382.1 \\
\end{tabular} & 3431.3 & 1715.5 & -1 & 0.5 & 1588.4 & -1.11 & 0.463 & 1652.3 & -1.05 & 0.482 \\
\hline
\end{tabular}

Table 5. List of downregulated genes of MT8148 in the presence of S-PRG eluate, which were observed in either MT8148 or UA159 under three different conditions using DNA microarray analysis. ${ }^{*} \log 2$ means Log2 ratio. "Change means Fold change. The Log2 ratio and Fold change were calculated by signal with each concentration of S-PRG eluate/signal without S-PRG eluate.

by an operon consisting of $p d h D, p d h A, p d h B$, and $p d h C$ genes, and a $p d h D$ defective mutant strain showed extremely reduced survival as compared with the parent strain ${ }^{15}$. Thus, S-PRG eluate likely affects the $p d h D$ gene, resulting in reduced bacterial survival. In addition, the $\lg$ operon $(g \lg B, g \lg C, g \lg D, g \lg A, g \lg P)$, which is involved in glycogen synthesis from glucose-1-phosphate via ADP-glucose $\mathrm{e}^{21,35}$, was downregulated in the presence of high concentrations of S-PRG eluate. Although strong inhibition was only observed in UA159, the lac operon ( $l a c A, l a c B, l a c C, l a c D, l a c F, l a c E$, lac $G$ ), which is involved in galactose and lactose metabolic pathways ${ }^{21}$, was also downregulated.

The S-PRG eluate could inhibit several in vitro properties related to the development of dental caries in $S$. mutans before the active growth phase. When we further analysed the inhibitory effects of S-PRG eluate against $S$. mutans in the post-logarithmic phase, the effects of the S-PRG eluate were less pronounced. These results indicated that a major role for the S-PRG eluate is the inhibition of $S$. mutans virulence and growth, which occurs before the active growth phase. Therefore, the inhibition of several in vitro properties of $S$. mutans before the 


\begin{tabular}{|c|c|c|c|c|c|c|c|c|c|c|c|}
\hline \multirow[b]{2}{*}{ Gene } & \multirow{2}{*}{$\begin{array}{l}\text { Accession } \\
\text { number }\end{array}$} & \multirow{2}{*}{\begin{tabular}{|l|} 
S-PRG \\
$\mathbf{0} \%$
\end{tabular}} & \multicolumn{3}{|c|}{ S-PRG 6.3\% } & \multicolumn{3}{|c|}{ S-PRG12.5\% } & \multicolumn{3}{|c|}{ S-PRG 25.0\% } \\
\hline & & & Signal & $\log 2 *$ & Change $^{*}$ & Signal & $\log 2^{*}$ & Change $^{*}$ & Signal & $\log 2 *$ & Change \\
\hline$b c c$ & \begin{tabular}{|l|}
721410.1 \\
\end{tabular} & 5980.6 & 1943.9 & -1.62 & 0.325 & 1876.8 & -1.67 & 0.314 & 1108.3 & -2.43 & 0.185 \\
\hline celR & \begin{tabular}{|l|}
721935.1 \\
\end{tabular} & 11936 & 1137.1 & -3.4 & 0.095 & 366.9 & -5.02 & 0.031 & 38.4 & -8.3 & 0.003 \\
\hline cilA & \begin{tabular}{|l|}
721415.1 \\
\end{tabular} & 5421.4 & 1804.4 & -1.59 & 0.332 & 1879 & -1.53 & 0.347 & 726.1 & -2.9 & 0.134 \\
\hline cilB & \begin{tabular}{|l|}
721414.1 \\
\end{tabular} & 3708.8 & 1459.6 & -1.34 & \begin{tabular}{|l|}
0.394 \\
\end{tabular} & 1488.8 & -1.32 & 0.402 & 712.4 & -2.38 & 0.192 \\
\hline cilG & \begin{tabular}{|l|}
721413.1 \\
\end{tabular} & 4245.9 & 1734 & -1.29 & \begin{tabular}{|l|}
0.408 \\
\end{tabular} & 1999.6 & -1.09 & 0.471 & 1059.9 & -2 & 0.249 \\
\hline citC & \begin{tabular}{|l|}
721405.1 \\
\end{tabular} & 1927.9 & 218.7 & -3.15 & 0.113 & 121.6 & -3.99 & 0.063 & 164.4 & -3.55 & 0.085 \\
\hline$c i t G$ & \begin{tabular}{|l|}
721406.1 \\
\end{tabular} & 1543.6 & 282.1 & -2.45 & \begin{tabular}{|l|}
0.183 \\
\end{tabular} & 138.2 & -3.48 & 0.089 & 183.1 & -3.1 & 0.117 \\
\hline citG2 & \begin{tabular}{|l|}
721416.1 \\
\end{tabular} & 5644.4 & 1906.9 & -1.56 & 0.338 & 1774.5 & -1.67 & 0.314 & 694.5 & -3.02 & 0.123 \\
\hline coaA & \begin{tabular}{|l|}
721513.1 \\
\end{tabular} & 126.2 & 39.1 & -1.69 & 0.31 & 49.8 & -1.34 & 0.395 & 54.6 & -1.21 & 0.433 \\
\hline comEA & \begin{tabular}{|l|}
721053.1 \\
\end{tabular} & 135.8 & 67.9 & -1 & 0.5 & 29.2 & -2.22 & 0.215 & 29.5 & -2.21 & 0.217 \\
\hline $\operatorname{com} Y A$ & \begin{tabular}{|l|}
722285.1 \\
\end{tabular} & 231.2 & 37.6 & -2.65 & 0.159 & 17.9 & -3.74 & 0.075 & 28.8 & -3.02 & 0.124 \\
\hline $\operatorname{com} Y B$ & \begin{tabular}{|l|}
722284.1 \\
\end{tabular} & 606.2 & 90 & -2.76 & \begin{tabular}{|l|}
0.148 \\
\end{tabular} & 42 & -3.87 & 0.069 & 69 & -3.14 & 0.113 \\
\hline $\operatorname{com} Y C$ & \begin{tabular}{|l|}
722283.1 \\
\end{tabular} & 903.7 & 109.7 & -3.05 & 0.121 & 45.5 & -4.34 & 0.049 & 102.2 & -3.14 & 0.113 \\
\hline $\operatorname{com} Y D$ & \begin{tabular}{|l|}
722282.1 \\
\end{tabular} & 750.9 & 89.6 & -3.13 & 0.114 & 38 & -4.34 & 0.05 & 70.7 & -3.43 & 0.093 \\
\hline galR & \begin{tabular}{|l|}
721293.1 \\
\end{tabular} & 998.6 & 467 & -1.1 & \begin{tabular}{|l|}
0.468 \\
\end{tabular} & 222.2 & -2.17 & 0.222 & 396.7 & -1.33 & 0.397 \\
\hline grpE & \begin{tabular}{|l|}
720560.1 \\
\end{tabular} & 40392.6 & 24381 & -0.72 & 0.603 & 15498.9 & -1.38 & 0.384 & 23261.7 & -0.8 & 0.576 \\
\hline$h s d M$ & \begin{tabular}{|l|}
721299.1 \\
\end{tabular} & 236.4 & 230.2 & -0.04 & 0.974 & 233.2 & -0.02 & 0.986 & 693.4 & 1.55 & 2.933 \\
\hline lacA & \begin{tabular}{|l|}
721844.1 \\
\end{tabular} & 1232.9 & 487.2 & -1.34 & 0.395 & 115.2 & -3.42 & 0.093 & 34 & -5.19 & 0.027 \\
\hline lacB & \begin{tabular}{|l|}
721843.1 \\
\end{tabular} & 3958.7 & 974.1 & -2.02 & 0.246 & 263.3 & -3.91 & 0.066 & 59.5 & -6.09 & 0.015 \\
\hline lacC & \begin{tabular}{|l|}
721842.1 \\
\end{tabular} & 2894.5 & 707.6 & -2.03 & 0.245 & 203.3 & -3.83 & 0.07 & 44.2 & -6.07 & 0.015 \\
\hline lacD & \begin{tabular}{|l|}
721841.1 \\
\end{tabular} & 2529.6 & 976.9 & -1.37 & 0.386 & 173.4 & -3.88 & 0.068 & 25.2 & -6.65 & 0.01 \\
\hline lacD2 & \begin{tabular}{|l|}
720591.1 \\
\end{tabular} & 1990.2 & 422.6 & -2.24 & 0.212 & 162.4 & -3.61 & 0.082 & 39.2 & -5.67 & 0.02 \\
\hline lacE & \begin{tabular}{|l|}
721839.1 \\
\end{tabular} & 4352.6 & 1160.3 & -1.91 & 0.267 & 303.3 & -3.85 & 0.07 & 71.2 & -5.93 & 0.016 \\
\hline lacF & \begin{tabular}{|l|}
721840.1 \\
\end{tabular} & 3438.8 & 936 & -1.88 & 0.272 & 227.8 & -3.92 & 0.066 & 38.3 & -6.54 & 0.011 \\
\hline lacG & \begin{tabular}{|l|}
721838.1 \\
\end{tabular} & \begin{tabular}{|l|}
30256.7 \\
\end{tabular} & 6224.5 & -2.28 & 0.206 & 1223.1 & -4.63 & 0.04 & 270.5 & -6.81 & 0.009 \\
\hline $\operatorname{lac} X$ & \begin{tabular}{|l|}
721837.1 \\
\end{tabular} & 2139.1 & 804.4 & -1.41 & \begin{tabular}{|l|}
0.376 \\
\end{tabular} & 251.6 & -3.09 & 0.118 & 84.2 & -4.67 & 0.039 \\
\hline lytR & \begin{tabular}{|l|}
721011.1 \\
\end{tabular} & 1717.4 & 772.8 & -1.15 & 0.45 & 841.5 & -1.03 & 0.49 & 419.1 & -2.04 & 0.244 \\
\hline $\operatorname{oadB}$ & \begin{tabular}{|l|}
721411.1 \\
\end{tabular} & \begin{tabular}{|l|}
11315.4 \\
\end{tabular} & 4350.1 & -1.38 & \begin{tabular}{|l|}
0.384 \\
\end{tabular} & 4811.2 & -1.23 & 0.425 & 2660.8 & -2.09 & 0.235 \\
\hline$p f l C$ & \begin{tabular}{|l|}
720930.1 \\
\end{tabular} & 1164.2 & 478.1 & -1.28 & 0.411 & 391.9 & -1.57 & 0.337 & 544.7 & -1.1 & 0.468 \\
\hline$p t c A$ & \begin{tabular}{|l|l|}
721934.1 \\
\end{tabular} & 7508.6 & 633.3 & -3.57 & 0.084 & 207.5 & -5.19 & 0.027 & 17.7 & -8.74 & 0.002 \\
\hline$p t c B$ & \begin{tabular}{|l|}
721936.1 \\
\end{tabular} & 615.6 & 239.6 & -1.37 & 0.388 & 103.5 & -2.58 & 0.167 & 21.7 & -4.84 & 0.035 \\
\hline$p t c C$ & \begin{tabular}{|l|}
721932.1 \\
\end{tabular} & 2921 & 366.2 & -3 & \begin{tabular}{|l|}
0.125 \\
\end{tabular} & 124.6 & -4.56 & 0.043 & 38.5 & -6.25 & 0.013 \\
\hline$p y c B$ & \begin{tabular}{|l|}
721417.1 \\
\end{tabular} & 22423.4 & 5598.4 & -2 & 0.25 & 4989.7 & -2.17 & 0.223 & 2210.2 & -3.34 & 0.099 \\
\hline $\operatorname{rgp} G$ & \begin{tabular}{|l|}
720710.1 \\
\end{tabular} & 1621.9 & 1575.5 & -0.04 & 0.971 & 1983.1 & 0.29 & 1.223 & 4685.6 & 1.53 & 2.889 \\
\hline $\operatorname{scn} E$ & \begin{tabular}{|l|}
722129.1 \\
\end{tabular} & 324.3 & 412.9 & 0.35 & 1.273 & 291.9 & -0.15 & 0.9 & 284 & -0.19 & 0.876 \\
\hline spaP & \begin{tabular}{|l|}
721042.1 \\
\end{tabular} & 3168.9 & 3842.9 & 0.28 & 1.212 & 2127.1 & -0.58 & 0.671 & 2296.4 & -0.47 & 0.724 \\
\hline$s s b 2$ & \begin{tabular}{|l|}
722266.1 \\
\end{tabular} & 769.7 & 369.5 & -1.06 & 0.48 & 271.3 & -1.51 & 0.352 & 308.6 & -1.32 & 0.401 \\
\hline trk & \begin{tabular}{|l|}
721902.1 \\
\end{tabular} & \begin{tabular}{|l|}
14957.3 \\
\end{tabular} & 11522.8 & -0.38 & \begin{tabular}{|l|}
0.77 \\
\end{tabular} & $\mid 10018.8$ & -0.58 & 0.67 & 3609 & -2.05 & 0.241 \\
\hline trkB & \begin{tabular}{|l|}
721901.1 \\
\end{tabular} & 10436.8 & 7856.4 & -0.41 & 0.753 & 7320 & -0.51 & 0.701 & 2494.6 & -2.06 & 0.239 \\
\hline wapA & \begin{tabular}{|l|}
721382.1 \\
\end{tabular} & 3891.4 & 2323.7 & -0.74 & 0.597 & 1931.4 & -1.01 & 0.496 & 568.7 & -2.78 & 0.146 \\
\hline
\end{tabular}

Table 6. List of downregulated genes of UA159 in the presence of S-PRG eluate, which were observed in either MT8148 or UA159 under three different conditions using DNA microarray analysis. ${ }^{*} \log 2$ means $\log 2$ ratio. \#Change means Fold change. The Log2 ratio and Fold change were calculated by signal with each concentration of S-PRG eluate/signal without S-PRG eluate.

growth phase in the presence of S-PRG eluate may be result from downregulation of genes such as those in the pdh operon and $g l g$ operons.

Another possible explanation for the inhibitory effects of S-PRG eluate on the in vitro cariogenic properties of $S$. mutans is that the S-PRG eluate may affect other $S$. mutans virulence genes since DNA microarray assays were performed under fixed incubation conditions. However, we did test various S-PRG eluate concentrations as well as different $S$. mutans strains. Therefore, further molecular biological analyses should be performed focusing on the inhibitory mechanisms of S-PRG eluate against other relevant in vitro cariogenic properties of $S$. mutans.

In the microarray analysis, S-PRG eluate most prominently repressed the expression of genes encoding the pyruvate dehydrogenase (PDH) complex, and the complex is known to be important for the bacterial growth and survival ${ }^{27}$. The PDH complex is also present in various bacterial species such as Mycobacterium tuberculosis and Escherichia coli ${ }^{36,37}$. Therefore, we thought that other oral streptococcal species may be growth inhibited by the S-PRG eluate prior to their active growth phase rather than following logarithmic growth phase. Based on 

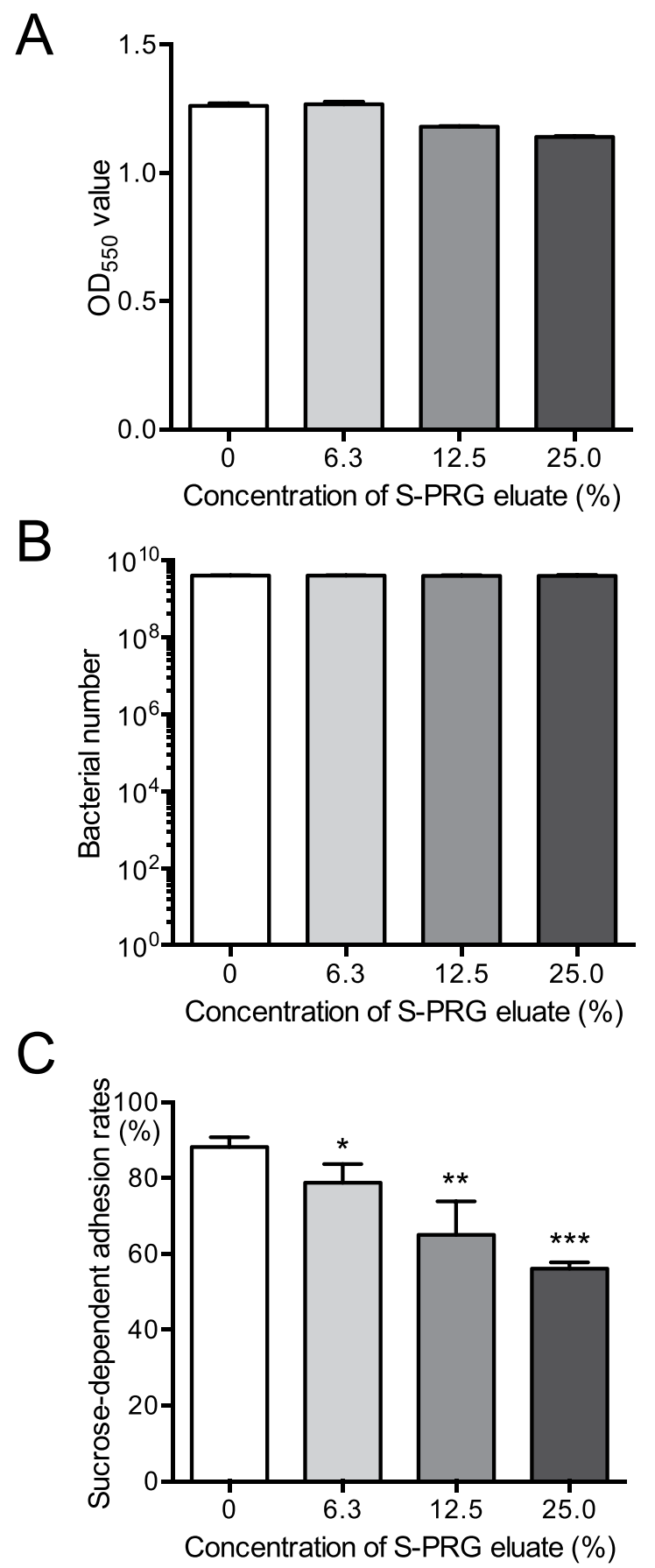

Figure 5. Sucrose-dependent adhesion of S. mutans MT8148 in the presence of various concentrations of S-PRG eluate. Bacterial growth for cells used in the sucrose-dependent adhesion assay was determined by $\mathrm{OD}_{550}$ values (A) and recovered bacterial numbers on MSB plates (B). (C) Sucrose-dependent adhesion rates. Significant differences were determined using ANOVA with Bonferroni correction. $* P<0.05$, $* * P<0.01$, and $* * * P<0.001$ versus no S-PRG eluate.

this hypothesis, we have added the results of bacterial growth with or without S-PRG eluate using Streptococcus sobrinus (similar cariogenic bacteria to S. mutans) and Streptococcus gordonii (non-cariogenic bacteria), both of which were growth inhibited in the presence of S-PRG eluate, especially before the growth phase. On the other hand, some of the cariogenic properties such as sucrose-dependent colonization are specific for $S$. mutans and $S$. sobrinus. Thus, we analyzed the inhibitory effects on several in-vitro cariogenic properties of S. sobrinus in the presence of S-PRG eluate, which showed that the S-PRG eluate inhibited the cariogenic properties of S. sobrinus most prominently prior to active growth phase rather after logarithmic growth similar to that observed with $S$. mutans. These results may indicate that S-PRG eluate can inhibit $S$. mutans as well as various oral streptococci in a similar manner. 
A

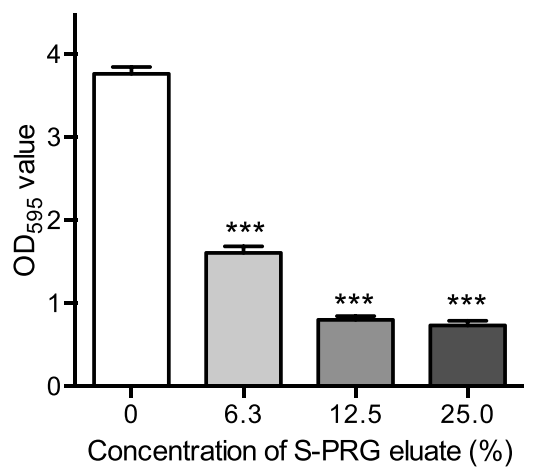

C

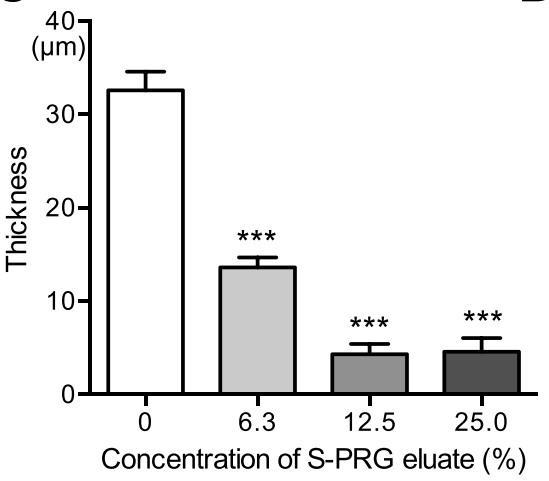

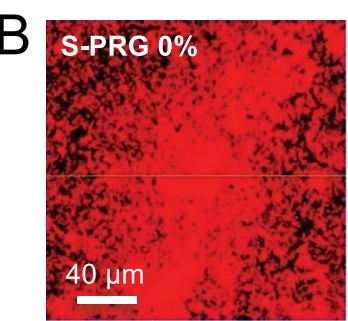
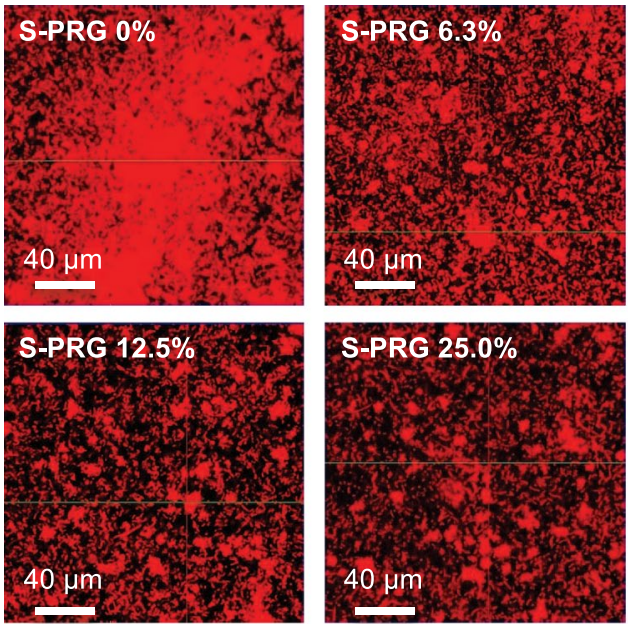

Concentration of S-PRG

$0 \%$

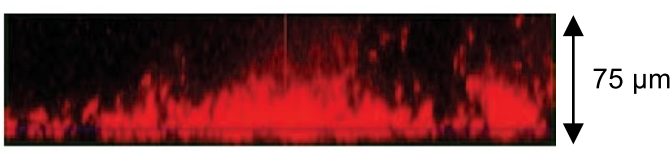

$6.3 \%$

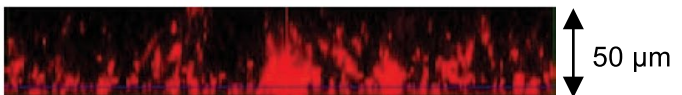

$12.5 \%$

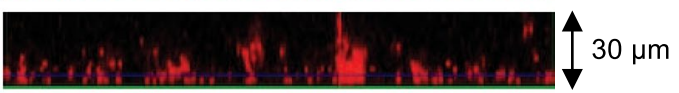

$25.0 \%$

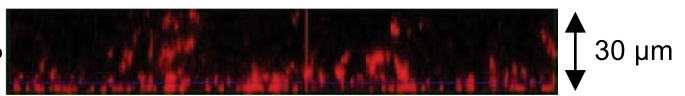

Figure 6. Biofilm formation by S. mutans MT8148 grown in BHI with $0.25 \%$ sucrose in the presence of various concentrations of S-PRG eluate. (A) Quantity of biofilm formation. (B) Representative images of formed biofilms using confocal scanning laser microscopy. (C) Biofilm thickness. (D) Representative images of biofilm thickness using confocal scanning laser microscopy. Significant differences were determined using ANOVA with Bonferroni correction. $* * * P<0.001$ versus no S-PRG eluate.

In summary, S-PRG eluates inhibited the bacterial growth of $S$. mutans and downregulated genes involved in sugar metabolism. In addition, the S-PRG eluate clearly inhibited several in vitro cariogenic properties of $S$. mutans. Taken together, our results suggest that the S-PRG eluate may be a useful tool for reducing dental caries due to its inhibitory effects on the bacterial growth and the sugar-dependent cariogenic properties of S. mutans.

\section{Methods}

S-PRG eluate preparations. S-PRG eluate was prepared as described previously ${ }^{38}$, and was provided by Shofu Inc. (Kyoto, Japan). Briefly, S-PRG filler was mixed with an equal amount of distilled water and mixed gently at room temperature for $24 \mathrm{~h}$, followed by centrifugation at $3,000 \times g, 23^{\circ} \mathrm{C}$ for $6 \mathrm{~h}$ to separate the filler and the liquid. The supernatant was then filtered (pore size: $0.45 \mu \mathrm{m}$ ) to remove any residual insoluble material and the resulting filtrate was used as the S-PRG eluate. The concentrations of ions released from S-PRG filler except for $\mathrm{F}^{-}$(i.e., $\mathrm{Al}^{3+}, \mathrm{BO}_{3}{ }^{3-}, \mathrm{Na}^{+}, \mathrm{SiO}_{3}{ }^{2-}$, and $\mathrm{Sr}^{2+}$ ) were measured by using an emission spectrophotometer (ICPS- 8000 , Shimadzu Co., Kyoto, Japan). In addition, the concentration of $\mathrm{F}^{-}$was confirmed with a $\mathrm{F}^{-}$electrode (Model 9609BNWP, Orion Research Inc., Beverly, MA, USA) using an ion selective electrode meter (Model 720 A, Orion Research Inc.). The ion concentrations of the S-PRG eluate were as follows: $\mathrm{Al}^{3+}=19.6 \mathrm{ppm}, \mathrm{BO}_{3}{ }^{3-}=1,656.5$ $\mathrm{ppm}, \mathrm{Na}^{+}=618.5 \mathrm{ppm}, \mathrm{SiO}_{3}{ }^{2-}=13.9 \mathrm{ppm}, \mathrm{Sr}^{2+}=126.8 \mathrm{ppm}$, and $\mathrm{F}^{-}=141.0 \mathrm{ppm}$. The S-PRG eluate was diluted with brain heart infusion (BHI) broth (Difco Laboratories) at concentration of $25 \%, 12.5 \%, 6.3 \%$, and $0 \%$, respectively, and was used in subsequent studies.

Bacterial strains and growth condition. S. mutans strains MT8148 and UA159 were selected from the stock culture collection in our laboratory ${ }^{39-41}$. In addition, S. sobrinus B13 and S. gordonii ATCC10558 were also used $^{28,29}$. Strains were confirmed to be S. mutans, S. sobrinus and S. gordonii based on their biochemical properties and observation of colony morphologies on MS with and without bacitracin agar plates. These strains were cultured in $\mathrm{BHI}$ broth at $37^{\circ} \mathrm{C}$ for $18 \mathrm{~h}$ and used in subsequent studies.

Growth inhibition assay. The growth inhibition assays were performed according to methods described previously with some modification ${ }^{42}$. Cells from overnight cultures of S. mutans MT8148 grown in BHI broth 
A

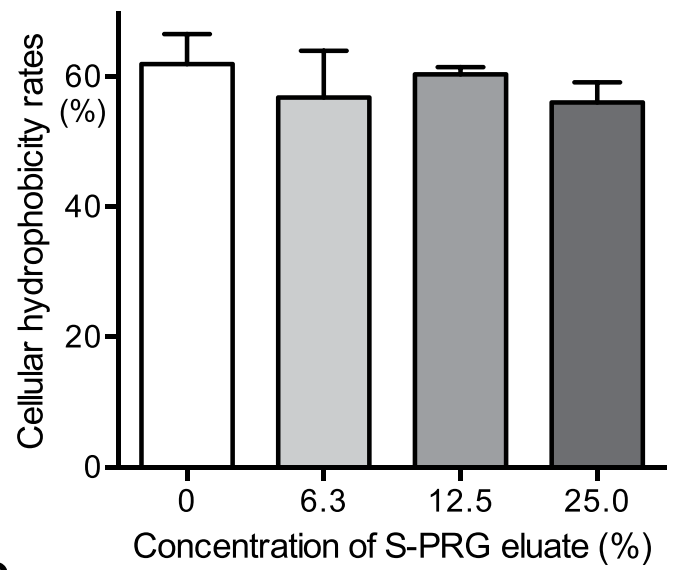

B

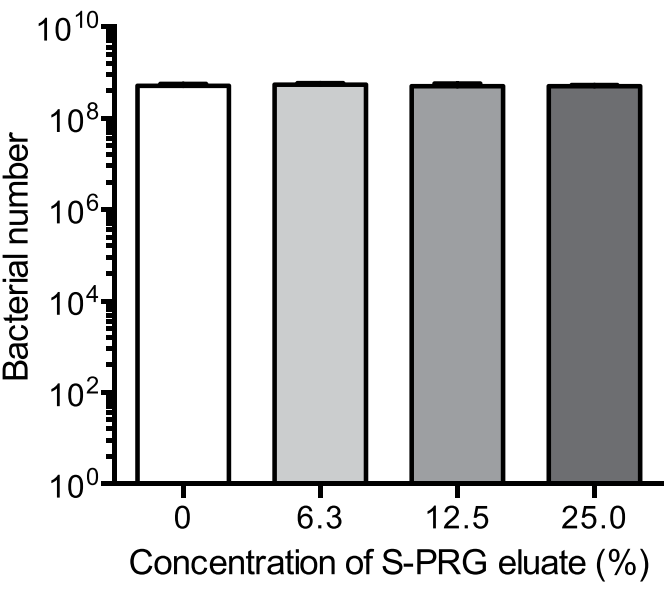

C

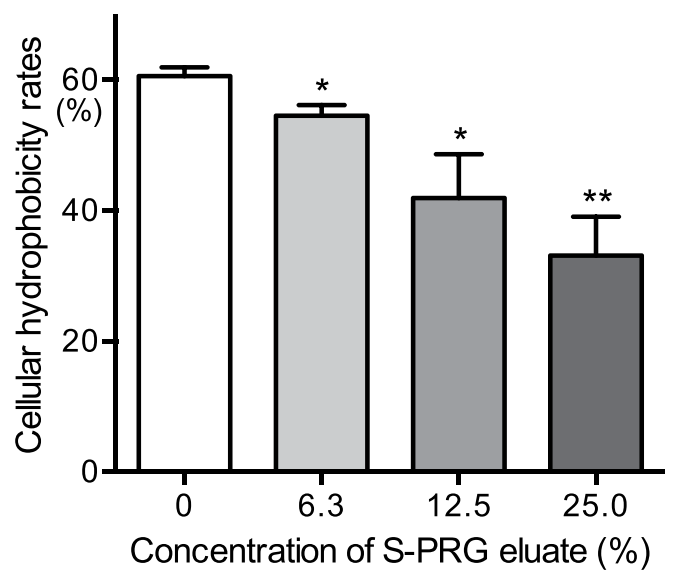

Figure 7. Cellular hydrophobicity of S. mutans MT8148 in the presence of various concentrations of S-PRG eluate. (A) Cellular hydrophobicity in the presence of S-PRG eluate. (B) Bacterial numbers used in the cellular hydrophobicity assay (C) Cellular hydrophobicity following the addition of S-PRG eluate $18 \mathrm{~h}$ before the assay. Significant differences were determined using ANOVA with Bonferroni correction. $* P<0.05$ and $* * P<0.01$ versus no S-PRG eluate.

were collected by centrifugation at 3,000 $\times g$ for $10 \mathrm{~min}$. We confirmed that bacterial suspensions adjusted in BHI broth to $\mathrm{OD}_{550}=1.0$ were equal to $1 \times 10^{9} \mathrm{CFU} / \mathrm{ml}$ by adding serial dilutions of the bacterial suspensions onto MSB agar plates. Using the suspensions, bacterial dilutions with final concentrations ranging from $1.0 \times 10^{3}$ to $1.0 \times 10^{8} \mathrm{CFU} / \mathrm{ml}$ with or without S-PRG eluate were prepared. After 18 -h incubation at $37^{\circ} \mathrm{C}$, bacterial growth was measured at $\mathrm{OD}_{550}$ and bacterial suspensions were then streaked onto MSB plates supplemented with $15 \%$ $(\mathrm{w} / \mathrm{v})$ sucrose and $0.2 \mathrm{U} / \mathrm{ml}$ of bacitracin and incubated anaerobically at $37^{\circ} \mathrm{C}$ for $48 \mathrm{~h}$. The numbers of colonies 
A

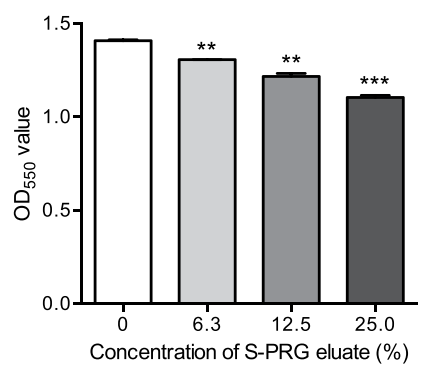

B

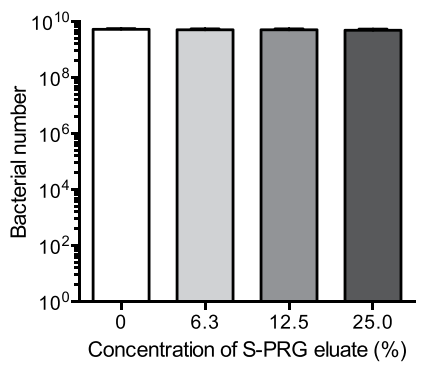

C

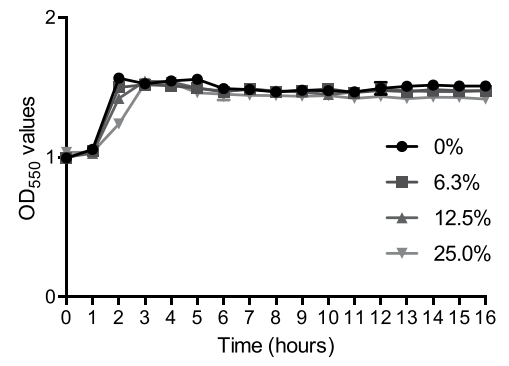

$\mathrm{D}$

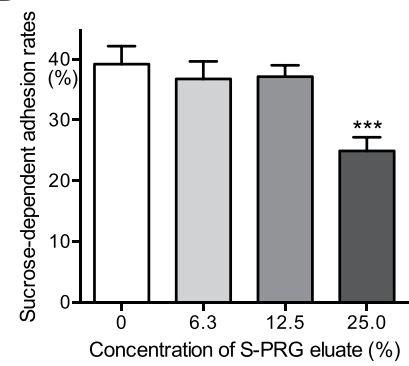

E

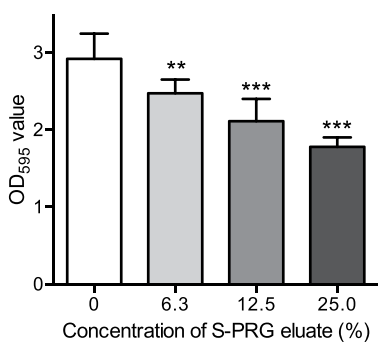

Figure 8. In vitro properties of $S$. mutans MT8148 in the late logarithmic phase in the presence of various concentrations of S-PRG eluate. (A, B) Bacterial growth by adding $1 \times 10^{9} \mathrm{CFU} / \mathrm{ml}$ of S. mutans with 18 -h incubation, which was determined by $\mathrm{OD}_{550}$ values in BHI broth (A) and recovered bacterial numbers on MSB plates (B). (C) Bacterial growth by adding $1 \times 10^{9} \mathrm{CFU} / \mathrm{ml}$ of $S$. mutans at multiple time points, which was determined by $\mathrm{OD}_{550}$ values in BHI broth. (D) Sucrose-dependent adhesion rates. (E) Quantitation of biofilm formation. Significant differences were determined using ANOVA with Bonferroni correction. $* P<0.05$, $* * P<0.01$, and $* * * P<0.001$ versus no $S-P R G$ eluate.

were counted after identifying the characteristic colony morphology of mutans streptococci. As for S. sobrinus B13 and S. gordonii ATCC10558, the inhibitory effects of S-PRG eluate on bacterial suspensions with concentrations of $1.0 \times 10^{5} \mathrm{CFU} / \mathrm{ml}$ were also analysed, since $S$. mutans was significantly inhibited by S-PRG eluate at this density. In addition, to monitor the kinetics of bacterial growth for MT8148, $\mathrm{OD}_{550}$ values of the bacterial suspensions were adjusted $1.0 \times 10^{7} \mathrm{CFU} / \mathrm{ml}$ with or without S-PRG eluate and monitored every 1 hour until the bacterial growth reached the stationary phase. In addition, survival of $1.0 \times 10^{7} \mathrm{CFU} / \mathrm{ml}$ of the bacteria added to $\mathrm{BHI}$ in the presence of each concentration of S-PRG eluate was monitored for 2 weeks by adding aliquots of the bacterial suspensions to MSB plates every 48 hours.

The growth of $S$. mutans MT8148 in late logarithmic phase was determined by a previously described method $^{43}$. S. mutans MT8148, which was grown for $24 \mathrm{~h}$ to reach stationary phase, was adjusted to a final concentration of $1.0 \times 10^{9} \mathrm{CFU} / \mathrm{ml}$ in $\mathrm{BHI}$ broth with or without S-PRG eluate. After a further 18 -h incubation at $37^{\circ} \mathrm{C}$, bacterial growth was measured at $\mathrm{OD}_{550}$ and bacterial suspensions were streaked onto MSB plates, followed by colony counting as described above. In addition, to monitor the kinetics of bacterial growth, the bacterial suspensions adjusted to a final concentration of $1.0 \times 10^{9} \mathrm{CFU} / \mathrm{ml}$ with or without S-PRG eluate were cultured at $37^{\circ} \mathrm{C}$ and $\mathrm{OD}_{550}$ values of the bacterial suspensions were measured every hour until the bacteria entered the stationary phase. As for S. sobrinus B13 and S. gordonii ATCC10558, $1.0 \times 10^{9} \mathrm{CFU} / \mathrm{ml}$ of the bacteria were incubated with S-PRG eluate at $37^{\circ} \mathrm{C}$ for $18 \mathrm{~h}$ and the bacterial suspensions were then streaked onto MSB plates, followed by colony counting as described above.

DNA microarray assays. A systematic analysis of gene alterations in $S$. mutans was performed using DNA microarrays to identify $S$. mutans gene expression affected by the S-PRG eluate, as described previously ${ }^{44}$. Briefly, $1.0 \times 10^{7} \mathrm{CFU} / \mathrm{ml}$ of $S$. mutans MT8148 and UA159 in BHI broth were cultured with each specified concentration of S-PRG eluate at $37^{\circ} \mathrm{C}$ for $18 \mathrm{~h}$. Amino-allyl amplified RNA was then obtained from total RNA using the Amino-allyl MessageAmp aRNA kit (Ambion, Inc., Austin, TX, USA). The purity, concentration, and quality of the RNA samples were confirmed with a NanoDrop One (Thermo Fisher Scientific) and Agilent 2100 bioanalyser (Agilent Technologies, Inc., Santa Clara, CA, USA). The purity and quality of RNA were assessed by nucleic acid absorbance at $A_{260} / A_{230}$ and $A_{260} / A_{280}$ of each sample and were more than 2.0, respectively. The concentrations of RNA of these samples ranged from 50 to $440 \mathrm{ng} / \mu \mathrm{l}$. All samples were used for microarray assays after adjustment to a minimum concentration $(50 \mathrm{ng} / \mu \mathrm{l})$. The microarray assays were carried out by Takara Bio. Inc. (Otsu, Japan) using products for microarray analysis manufactured by Agilent Technologies, according to the manufacturer's protocols. Briefly, Cy3 complimentary RNA was labelled with a Low Input Quick Amp Labeling Kit, One-Color (Agilent Technologies), and the Cy3-Labeled complimentary RNA was hybridized with the complete genome of $S$. mutans UA159 assembled with the Agilent Expression Array kit. After washing with Gene Expression Wash Buffers Pack (Agilent Technologies), the hybridization images were analysed using an Agilent Microarray Scanner (G2565CA) (Agilent Technologies). Quantitative data were obtained using Agilent Feature 
A

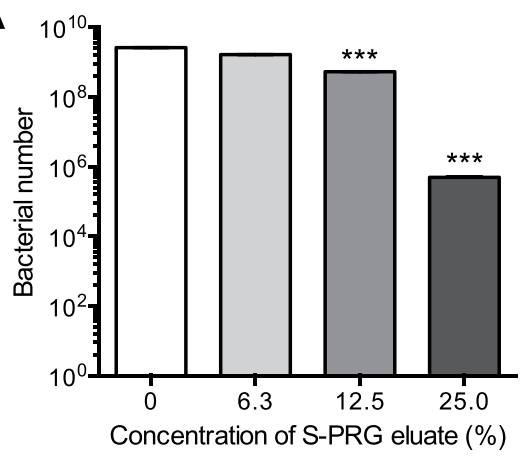

C

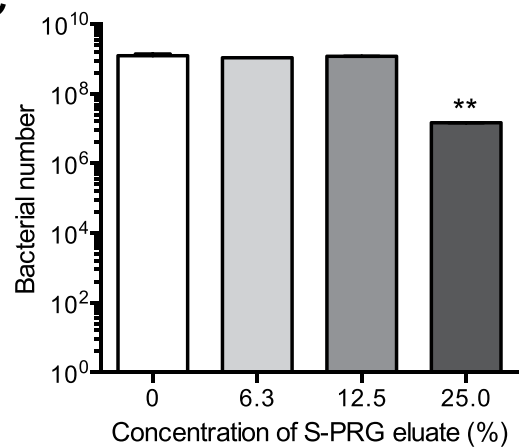

E

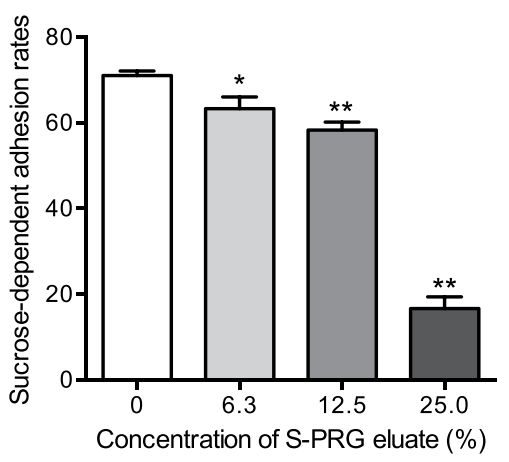

G

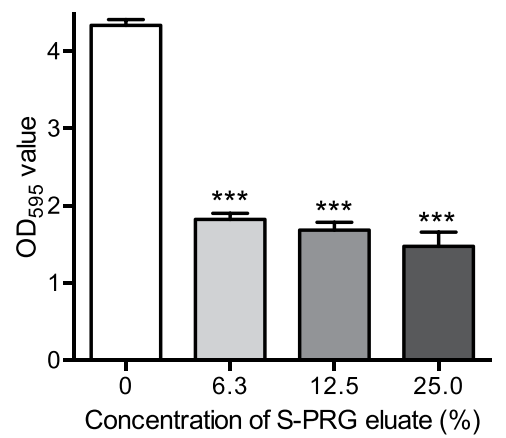

B

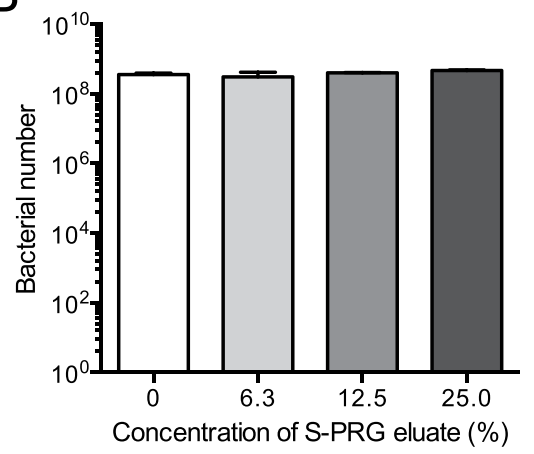

$\mathrm{D}$

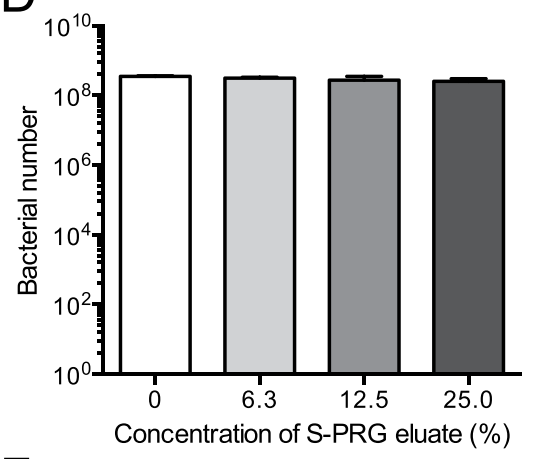

F

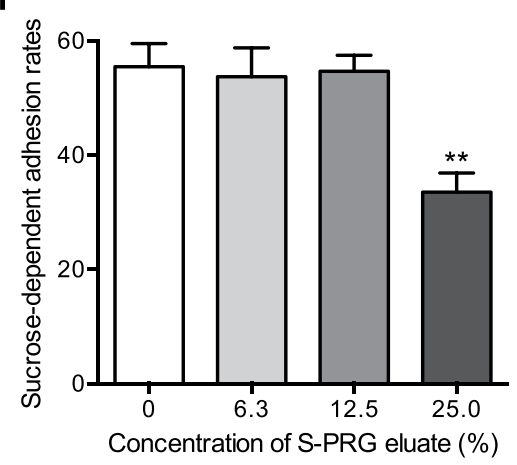

$\mathrm{H}$

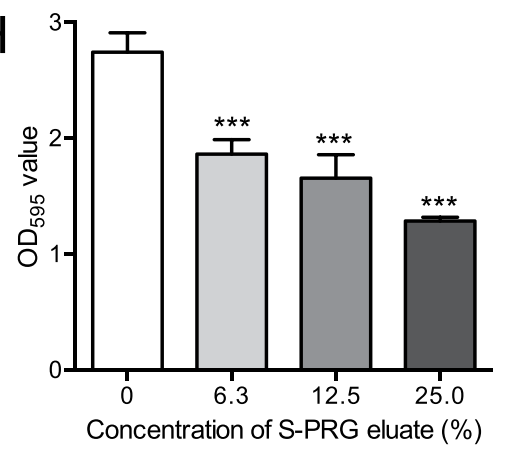

Figure 9. The in vitro properties of Streptococcus sobrinus B13 and Streptococcus gordonii ATCC10558 in the presence of various concentrations of S-PRG eluate. Bacterial growth using S. sobrinus before reaching the logarithmic phase (adjusted to $\left.1 \times 10^{5} \mathrm{CFU} / \mathrm{ml}\right)(\mathbf{A})$ and in the post-logarithmic phase (adjusted to $1 \times 10^{9}$ $\mathrm{CFU} / \mathrm{ml}$ ) (B) following $18 \mathrm{~h}$ incubation, which was determined by recovered bacterial numbers on MSB plates. Bacterial growth using S. gordonii reaching the logarithmic phase (adjusted to $\left.1 \times 10^{5} \mathrm{CFU} / \mathrm{ml}\right)(\mathrm{C})$ and in the post-logarithmic phase (adjusted to $1 \times 10^{9} \mathrm{CFU} / \mathrm{ml}$ ) (D) with $18 \mathrm{~h}$ incubations, which was determined by recovered bacterial numbers on MSB plates. Sucrose-dependent adhesion rates using bacterial suspensions of S. sobrinus B13 adjusted before reaching the logarithmic phase (adjusted to $\left.1 \times 10^{7} \mathrm{CFU} / \mathrm{ml}\right)(\mathbf{E})$ and in the post-logarithmic phase (adjusted to $\left.1 \times 10^{9} \mathrm{CFU} / \mathrm{ml}\right)(\mathbf{F})$, respectively. Quantitation of biofilm formation using bacterial suspensions of $S$. sobrinus $\mathrm{B} 13$ adjusted to $1 \times 10^{7} \mathrm{CFU} / \mathrm{ml}(\mathbf{G})$ and $1 \times 10^{9} \mathrm{CFU} / \mathrm{ml}(\mathbf{H})$, respectively. Significant differences were determined using ANOVA with Bonferroni correction. $* P<0.05$, ** $P<0.01$, and $* * * P<0.001$ versus no $S-P R G$ eluate. 
Extraction software (Agilent Technologies) and corrections for background signal intensity for the data were performed using a method, previously described ${ }^{45}$. Altered genes were identified using three different comparisons for each S. mutans strain and focused on the following S-PRG eluate concentrations: $0 \%$ versus $6.3 \%, 0 \%$ versus $12.5 \%$, and $0 \%$ versus $25.0 \%$. In addition, altered genes using two different comparisons for each $S$. mutans strain were also determined using S-PRG eluate concentrations of $0 \%$ versus $12.5 \%$ and $0 \%$ versus $25.0 \%$. We selected genes with changes of increase or decrease greater than 1.0 of Log2 ratio in presence or absence of the indicated concentrations of eluate.

Sucrose-dependent adhesion. Sucrose-dependent adhesion to a glass surface was analysed as previously described with some modification ${ }^{24}$. Cells from overnight cultures of S. mutans MT8148 and S. sobrinus B13 were collected by centrifugation at 3,000 $\times g$ for $10 \mathrm{~min}$, respectively. Cultures were adjusted in BHI broth containing $1 \%$ sucrose to a final concentration of $1.0 \times 10^{7} \mathrm{CFU} / \mathrm{ml}$ with or without S-PRG eluate. Bacterial suspensions were then cultured at $37^{\circ} \mathrm{C}$ for $18 \mathrm{~h}$ at a $30^{\circ}$ angle. After incubation, both adhesive and non-adhesive cells were measured by $\mathrm{OD}_{550}$ values and were streaked onto MSB plates to confirm the bacterial number in the culture tubes. In addition, culture tubes were also prepared other than those for the confirmation of the bacterial numbers were used for the sucrose-dependent adhesion assay. The culture tubes were vigorously vibrated with a vortex mixer for $3 \mathrm{~s}$ and non-adhesive cells were transferred to fresh tubes. Cells remaining on the glass surface (adhesive cells) were removed using a rubber scraper and suspended in $3 \mathrm{ml}$ of water. Both adhesive and non-adhesive cells were dispersed by ultrasonication, and the cell masses were determined by densitometry at $\mathrm{OD}_{550}$. Total cells were calculated as $\mathrm{OD}_{550}$ (adhesive cells + non-adhesive cells), and the percent adherence was calculated as $100 \times \mathrm{OD}_{550}$ (adhesive cells)/OD 550 (total cells).

Sucrose-dependent adhesion of S. mutans MT8148 and S. sobrinus B13 in the late logarithmic phase was determined according to a method described previously ${ }^{43}$. These bacteria were grown for $24 \mathrm{~h}$ to reach the stationary phase and were adjusted to a final concentration of $1.0 \times 10^{9} \mathrm{CFU} / \mathrm{ml}$ in $\mathrm{BHI}$ broth containing $1 \%$ sucrose with or without S-PRG eluate. Aliquots were cultured at $37^{\circ} \mathrm{C}$ for $18 \mathrm{~h}$ at a $30^{\circ}$ angle. Adherence rates were calculated as described above.

Biofilm assay. The quantity of formed biofilms was assessed as previously described with some modification $^{46,47}$. Human saliva collected from a healthy volunteer was centrifuged at $12,000 \times g$ for $10 \mathrm{~min}$ and the supernatant was filtered (pore size: $0.45 \mu \mathrm{m}$ ). The supernatant was diluted 1:3 with Milli-Q water to produce $25 \%$ saliva and coated 96-well polystyrene microtiter plates for $2 \mathrm{~h}$. Cells from overnight cultures of $S$. mutans MT8148 or $S$. sobrinus B13 were collected by centrifugation at 3,000 $\times \mathrm{g}$ for $10 \mathrm{~min}$. Cultures were adjusted to $1.0 \times 10^{7} \mathrm{CFU} /$ $\mathrm{ml}$ in $\mathrm{BHI}$ broth containing $0 \%, 0.25 \%$ and $1 \%$ sucrose with or without S-PRG eluate. Next, $200 \mu$ l of the bacterial suspensions were added to 96 -well polystyrene microtiter plates coated with human saliva. After incubation at $37^{\circ} \mathrm{C}$ for $24 \mathrm{~h}$, the plates were washed three times with phosphate-buffered saline (PBS) to remove loosely bound bacteria. Biofilms were fixed with $25 \%$ formaldehyde for $10 \mathrm{~min}$ and stained with $1 \%$ crystal violet in water (Sigma-Aldrich) for $15 \mathrm{~min}$ at room temperature. Next, the plates were washed three times and dissolved in $95 \%$ ethanol before quantification of the absorbance at $595 \mathrm{~nm}$ with an enzyme-linked immunosorbent assay microplate reader (Thermo Fisher Scientific, Waltham, MA, USA).

Biofilm formation by S. mutans MT8148 and S. sobrinus B13 in late logarithmic phase was determined as follows. The bacteria were grown for $24 \mathrm{~h}$ to reach the stationary phase and adjusted in BHI broth containing $0.25 \%$ sucrose to a final concentration of $1.0 \times 10^{9} \mathrm{CFU} / \mathrm{ml}$ with or without S-PRG eluate. Next, $200 \mu \mathrm{l}$ of the bacterial suspensions were added to 96 -well plates coated with $25 \%$ saliva followed by incubation at $37^{\circ} \mathrm{C}$ for $24 \mathrm{~h}$. Analysis of biofilm formation was then performed as described above.

Microscopic observation of in vitro biofilms. Quantitative and structural analysis of biofilms by confocal laser scanning microscopy was performed as described previously with some modifications ${ }^{48}$. Cells from overnight cultures of $S$. mutans MT8148 were collected by centrifugation at $3,000 \times g$ for 10 min. Bacterial cells were next resuspended in $1 \mathrm{ml}$ of Milli-Q water with $5 \mu \mathrm{l}$ of $10 \mathrm{mM}$ hexidium iodide (Invitrogen, Carlsbad, CA, USA) and incubated in the dark for $15 \mathrm{~min}$ at room temperature. The bacterial suspension was adjusted in BHI broth containing $0.25 \%$ sucrose to each specified cell concentration with or without S-PRG eluate. Next, $200 \mu$ l of the bacterial suspension were added to a chambered cover glass system (CultureWell ${ }^{\mathrm{TM}}$, Grace Bio Labs, Bend, OR, USA) coated with filtered human saliva. The chamber was then incubated at $37^{\circ} \mathrm{C}$ for $18 \mathrm{~h}$ in the dark. At the end of the experimental period, non-attached $S$. mutans cells were washed with PBS and biofilms were observed by confocal scanning laser microscopy using a TCS-SP5 microscope (Leica Microsystems GmbH, Wetzlar, Germany) with reflected laser light at $488 \mathrm{~nm}$, as well as a DMI6000 B fluorescence microscope (Leica) and a $63 \times$ oil immersion objective. Biofilm thickness was measured as follows: an image taken in the $\mathrm{z}$-axis was divided into 10 sections and the thickness of the central portion was measured. The mean value and standard deviation for the thickness were then calculated.

Hydrophobic interaction. Cellular hydrophobicity was determined using $\mathrm{n}$-hexadecane (Wako) as previously described with some modifications ${ }^{26}$. Overnight cultures of $S$. mutans MT8148 were collected by centrifugation at $3,000 \times g$ for $10 \mathrm{~min}$. Cultures were adjusted to $\mathrm{OD}_{550}$ of 0.6 with or without S-PRG eluate Next, $0.2 \mathrm{ml}$ of $\mathrm{n}$-hexadecane was added to $3 \mathrm{ml}$ of bacterial cells and then uniformly agitated with a vortex mixer for $1 \mathrm{~min}$ to induce hydrophobic interaction between the test strain and n-hexadecane. The mixture was left to stand for $10 \mathrm{~min}$ at room temperature and the optical density of the aqueous phase was determined at $\mathrm{OD}_{550}$. The incorporation rate was calculated as follows: $\left[1-\mathrm{OD}_{550}\right.$ (aqueous phase of the tube containing the cell suspensions with added $n$-hexadecane) $/ \mathrm{OD}_{550}$ (aqueous phase of the tube containing only cell suspensions) $\left.] \times 100(\%)\right]$. The results are shown as the mean $\pm \mathrm{SD}$ from four independent experiments. 
Cellular hydrophobicity using pre-logarithmic S. mutans cells pretreated with S-PRG eluate was also evaluated as follows. S. mutans MT8148 was added at a final concentration of $1.0 \times 10^{7} \mathrm{CFU} / \mathrm{ml}$ in BHI broth with or without S-PRG eluate. After the bacterial suspensions were incubated at $37^{\circ} \mathrm{C}$ for $18 \mathrm{~h}$, cultures were adjusted to $\mathrm{OD}_{550}$ of 0.6 and the bacterial suspensions were streaked onto MSB plates to confirm the bacterial numbers. Additional bacterial cultures adjusted to $\mathrm{OD}_{550}$ of 0.6 with or without S-PRG eluate were prepared to use for the following the cellular hydrophobicity assays, as described above.

Statistical analysis. Statistical analyses were conducted using GraphPad Prism 6 (GraphPad Software Inc., La Jolla, CA, USA). Intergroup differences were analysed using an analysis of variance (ANOVA) with Bonferroni correction. Results were considered to be significantly different at $P<0.05$.

\section{References}

1. Hamada, S. \& Slade, H. D. Biology, immunology, and cariogenicity of Streptococcus mutans. Microbiol Rev 44, 331-384 (1980).

2. Touger-Decker, R. \& van Loveren, C. Sugars and dental caries. Am J Clin Nutr 78, 881-892 (2003).

3. Randall, R. C. \& Wilson, N. H. Glass-ionomer restoratives: a systematic review of a secondary caries treatment effect. J Dent Res 78 , 628-637 (1999).

4. Imazato, S. Bio-active restorative materials with antibacterial effects: new dimension of innovation in restorative dentistry. Dent Mater J 28, 11-19 (2009).

5. Sicca, C., Bobbio, E., Quartuccio, N., Nicolò, G. \& Cistaro, A. Prevention of dental caries: A review of effective treatments. J Clin Exp Dent 8, 604-610 (2016)

6. Ikemura, K. et al. Optimizing filler content in an adhesive system containing pre-reacted glass-ionomer fillers. Dent Mater 19, $137-146$ (2003).

7. Shimazu, K., Ogata, K. \& Karibe, H. Caries-preventive effect of fissure sealant containing surface reaction-type pre-reacted glass ionomer filler and bonded by self-etching primer. J Clin Pediatr Dent. 36, 343-347 (2012).

8. Ma, S. et al. Effects of a coating resin containing S-PRG filler to prevent demineralization of root surfaces. Dent Mater J31, 909-915 (2012).

9. Suzuki, N. et al. Effects of S-PRG eluate on oral biofilm and oral malodor. Arch Oral Biol 59, 407-413 (2014).

10. Ito, S. et al. Effects of surface pre-reacted glass-ionomer fillers on mineral induction by phosphoprotein. J Dent 39, 72-79 (2011).

11. Yoneda, M., et al Effect of S-PRG Eluate on Biofilm Formation and Enzyme Activity of Oral Bacteria. Int J Dent. 2012, ID 814913, 6 pages (2012).

12. Hotta, M., Morikawa, T., Tamura, D. \& Kusakabe, S. Adherence of Streptococcus sanguinis and Streptococcus mutans to saliva-coated S-PRG resin blocks. Dent Mater J 33, 261-267 (2014).

13. Miki, S. et al. Antibacterial activity of resin composites containing surface pre-reacted glass-ionomer (S-PRG) filler. Dent Mater 32, 1095-1102 (2016).

14. Klein, M. I., Hwang, G., Santos, P. H., Campanella, O. H. \& Koo, H. Streptococcus mutans-derived extracellular matrix in cariogenic oral biofilms. Front Cell Infect Microbiol 5-10 (2015).

15. Busuioc, M., Buttaro, B. A. \& Piggot, P. J. The pdh operon is expressed in a subpopulation of stationary-phase bacteria and is important for survival of sugar-starved Streptococcus mutans. J Bacteriol 192, 4395-4402 (2010).

16. Sato, Y., Okamoto-Shibayama, K. \& Azuma, T. Glucose-PTS Involvement in Maltose Metabolism by Streptococcus mutans. Bull Tokyo Dent Coll 56, 93-103 (2015).

17. Renye, J. A. Jr., Piggot, P. J., Daneo-Moore, L. \& Buttaro, B. A. Persistence of Streptococcus mutans in stationary-phase batch cultures and biofilms. Appl Environ Microbiol. 70, 6181-6187 (2004).

18. Korithoski, B., Lévesque, C. M. \& Cvitkovitch, D. G. The involvement of the pyruvate dehydrogenase Elalpha subunit, in Streptococcus mutans acid tolerance. FEMS Microbiol Lett 289, 13-19 (2008).

19. Busuioc, M., Mackiewicz, K., Buttaro, B. A. \& Piggot, P. J. Role of intracellular polysaccharide in persistence of Streptococcus mutans. J Bacteriol 191, 7315-7322 (2009).

20. Asención Diez, M. D., Demonte, A. M. \& Guerrero, S. A, Ballicora, M. A., Iglesias, A. A. The ADP-glucose pyrophosphorylase from Streptococcus mutans provides evidence for the regulation of polysaccharide biosynthesis in Firmicutes. Mol Microbiol 90, 1011-1027 (2013).

21. Zeng, L., Das, S. \& Burne, R. A. Utilization of lactose and galactose by Streptococcus mutans: transport, toxicity, and carbon catabolite repression. J Bacteriol 192, 2434-2444 (2010).

22. Lunsford, R. D. \& Roble, A. G. comYA, a gene similar to comGA of Bacillus subtilis, is essential for competence-factor-dependent DNA transformation in Streptococcus gordonii. J Bacteriol. 179, 3122-3126 (1997).

23. Merritt, J., Qi, F. \& Shi, W. A. A unique nine-gene comY operon in Streptococcus mutans. Microbiology 151, 157-166 (2005).

24. Kawabata, S. \& Hamada, S. Studying biofilm formation of mutans streptococci. Methods Enzymol 310, 513-523 (1999).

25. Rosenberg, M., Judes, H. \& Weiss, E. Cell surface hydrophobicity of dental plaque microorganisms in situ. Infect Immun. 42, 831-834 (1983).

26. Rosenberg, M., Gutnick, D. \& Rosenberg, E. Adherence of bacteria to hydrocarbons: a simple method for measuring cell-surface hydrophobicity. FEMS Microbiol Lett 9, 29-33 (1980).

27. Krzyściak, W. et al. The usefulness of biotyping in the determination of selected pathogenicity determinants in Streptococcus mutans. BMC Microbiol 14, 194 (2014).

28. Kobayashi, S., Koga, K., Hayashida, O., Nakano, Y. \& Hasegawa, Y. Glucan-binding domain of a glucosyltransferase from Streptococcus sobrinus: isolation of a 55-kilodalton peptide from a trypsin digest of glucosyltransferase prebound to insoluble glucan. Infect Immun 57, 2210-2213 (1989).

29. Nagata, E., de Toledo, A. \& Oho, T. Invasion of human aortic endothelial cells by oral viridans group streptococci and induction of inflammatory cytokine production. Mol Oral Microbiol 26, 78-88 (2011).

30. Abinaya, S.,P. \& Gautam, P. Studies on the biofilm produced by Pseudomonas aeruginosa grown in different metal fatty acid salt media and its application in biodegradation of fatty acids and bioremediation of heavy metal ions. Can J Microbiol 63, 61-73 (2017).

31. McLean, R. J., Fortin, D. \& Brown, D. A. Microbial metal-binding mechanisms and their relation to nuclear waste disposal. Can J Microbiol 42, 392-400 (1996).

32. Wloka, M., Rehage, H., Flemming, H.-C. \& Wingender, J. Structure and rheological behaviour of the extracellular polymeric substance network of mucoid Pseudomonas aeruginosa biofilms. Biofilms 2, 275-283 (2005).

33. Paik, S., Brown, A., Munro, C. L., Cornelissen, C. N. \& Kitten, T. The sloABCR operon of Streptococcus mutans encodes an Mn and Fe transport systemrequired for endocarditis virulence and its Mn-dependent repressor. J Bacteriol 185, 5967-5975 (2003).

34. Binepal, G. et al. Trk2 Potassium Transport System in Streptococcus mutans and Its Role in Potassium Homeostasis, Biofilm Formation, and Stress Tolerance. J Bacteriol 198, 1087-1100 (2016).

35. Carlsson, J., Kujala, U. \& Edlund, M. B. Pyruvate dehydrogenase activity in Streptococcus mutans. Infect Immun. 49, 674-678 (1985).

36. Xu, S., Yang, Y., Jin, R., Zhang, M. \& Wang, H. Purification and characterization of a functionally active Mycobacterium tuberculosis prephenatedehydrogenase. Protein Expr Purif 49, 151-158 (2006). 
37. Chen, S., Vincent, S., Wilson, D. B. \& Ganem, B. Mapping of chorismate mutase and prephenate dehydrogenase domains in the Escherichia coli T-protein. Eur J Biochem 270, 757-763 (2003).

38. Fujimoto, Y. et al. Detection of ions released from S-PRG fillers and their modulation effect. Dent Mater J 29, 392-397 (2010).

39. Ooshima, T., Izumitani, A., Sobue, S. \& Hamada, S. Cariostatic effect of palatinose on experimental dental caries in rats. Jpn. J Med Sci Biol. 36, 219-223 (1983).

40. Miyatani, F. et al. Relationship between Cnm-positive Streptococcus mutans and cerebral microbleeds in humans. Oral Dis 21, 886-893 (2015)

41. Ajdić, D. et al. Genome sequence of Streptococcus mutans UA159, a cariogenic dental pathogen. Proc Natl Acad Sci USA 99, 14434-14439 (2002).

42. Sasaki, H. et al. Antibacterial activity of polyphenol components in oolong tea extract against Streptococcus mutans. Caries Res 38, 2-8 (2004).

43. Ooshima, T. et al. Contributions of three glycosyltransferases to sucrose-dependent adherence of Streptococcus mutans. J Dent Res 80, 1672-1677 (2001).

44. Park, S. N. et al Antimicrobial mechanism of oleanolic and ursolic acids on Streptococcus mutans UA159. Curr Microbiol (in press).

45. Zahurak, M. et al. Pre-processing Agilent microarray data. BMC Bioinformatics 8, 142 (2007).

46. Mattos-Graner, R. O. et al. Cloning of the Streptococcus mutans gene encoding glucan binding protein B and analysis of genetic diversity and protein production in clinical isolates. Infect. Immun. 69, 6931-6941 (2001).

47. Ardin, A. C. et al. Identification and functional analysis of an ammonium transporter in Streptococcus mutans. PLoS One 9, e107569 (2014).

48. Kuboniwa, M. et al. Streptococcus gordonii utilizes several distinct gene functions to recruit Porphyromonas gingivalis into a mixed community. Mol Microbiol 60, 121-139 (2006).

\section{Acknowledgements}

The authors thank Prof. Howard K. Kuramitsu, State University of New York at Buffalo for editing the manuscript. This work was supported by the Fund for Scientific Promotion of SHOFU Inc., Kyoto, Japan. All authors read and approved the final manuscript.

\section{Author Contributions}

R.N. designed the entire study under the supervision of K.N. R.N., Y.M. and S.M. performed the experiments, and data interpretation was conducted by R.N. Y.M., K.N., R.N. and K.N. wrote the manuscript, which all authors read and approved.

\section{Additional Information}

Supplementary information accompanies this paper at https://doi.org/10.1038/s41598-018-23354-x.

Competing Interests: The authors declare no competing interests.

Publisher's note: Springer Nature remains neutral with regard to jurisdictional claims in published maps and institutional affiliations.

(1) Open Access This article is licensed under a Creative Commons Attribution 4.0 International

License, which permits use, sharing, adaptation, distribution and reproduction in any medium or format, as long as you give appropriate credit to the original author(s) and the source, provide a link to the Creative Commons license, and indicate if changes were made. The images or other third party material in this article are included in the article's Creative Commons license, unless indicated otherwise in a credit line to the material. If material is not included in the article's Creative Commons license and your intended use is not permitted by statutory regulation or exceeds the permitted use, you will need to obtain permission directly from the copyright holder. To view a copy of this license, visit http://creativecommons.org/licenses/by/4.0/.

(c) The Author(s) 2018 